University of Windsor

Scholarship at UWindsor

$1-1-2007$

\title{
Seasonal variation in the duetting behaviour of rufous-and-white wrens (Thryothorus rufalbus).
}

Stephanie Marie Topp

University of Windsor

Follow this and additional works at: https://scholar.uwindsor.ca/etd

\section{Recommended Citation}

Topp, Stephanie Marie, "Seasonal variation in the duetting behaviour of rufous-and-white wrens (Thryothorus rufalbus)." (2007). Electronic Theses and Dissertations. 6958.

https://scholar.uwindsor.ca/etd/6958

This online database contains the full-text of PhD dissertations and Masters' theses of University of Windsor students from 1954 forward. These documents are made available for personal study and research purposes only, in accordance with the Canadian Copyright Act and the Creative Commons license-CC BY-NC-ND (Attribution, Non-Commercial, No Derivative Works). Under this license, works must always be attributed to the copyright holder (original author), cannot be used for any commercial purposes, and may not be altered. Any other use would require the permission of the copyright holder. Students may inquire about withdrawing their dissertation and/or thesis from this database. For additional inquiries, please contact the repository administrator via email (scholarship@uwindsor.ca) or by telephone at 519-253-3000ext. 3208. 
SEASONAL VARIATION IN THE DUETTING BEHAVIOUR OF RUFOUSAND-WHITE WRENS (THRYOTHORUS RUFALBUS)

by

STEPHANIE MARIE TOPP

\begin{abstract}
A Thesis
Submitted to the Faculty of Graduate Studies and Research through Biological Sciences

in Partial Fulfillment of the Requirements for the Degree of Master of Science at the

University of Windsor
\end{abstract}

Windsor, Ontario, Canada

2007

ㅇ S. M. Topp, 2007 


$\begin{array}{ll}\begin{array}{l}\text { Library and } \\ \text { Archives Canada }\end{array} & \begin{array}{l}\text { Bibliothèque et } \\ \text { Archives Canada }\end{array} \\ \begin{array}{l}\text { Published Heritage } \\ \text { Branch }\end{array} & \begin{array}{l}\text { Direction du } \\ \text { Patrimoine de l'édition }\end{array} \\ \begin{array}{l}\text { 395 Wellington Street } \\ \text { Ottawa ON K1A ON4 }\end{array} & \begin{array}{l}\text { 395, rue Wellington } \\ \text { Ottawa ON K1A ON4 } \\ \text { Canada }\end{array}\end{array}$

Your file Votre référence ISBN: 978-0-494-34983-0 Our file Notre référence ISBN: 978-0-494-34983-0

NOTICE:

The author has granted a nonexclusive license allowing Library and Archives Canada to reproduce, publish, archive, preserve, conserve, communicate to the public by telecommunication or on the Internet, loan, distribute and sell theses worldwide, for commercial or noncommercial purposes, in microform, paper, electronic and/or any other formats.

The author retains copyright ownership and moral rights in this thesis. Neither the thesis nor substantial extracts from it may be printed or otherwise reproduced without the author's permission.
AVIS:

L'auteur a accordé une licence non exclusive permettant à la Bibliothèque et Archives Canada de reproduire, publier, archiver, sauvegarder, conserver, transmettre au public par télécommunication ou par l'Internet, prêter, distribuer et vendre des thèses partout dans le monde, à des fins commerciales ou autres, sur support microforme, papier, électronique et/ou autres formats.

L'auteur conserve la propriété du droit d'auteur et des droits moraux qui protège cette thèse. $\mathrm{Ni}$ la thèse ni des extraits substantiels de celle-ci ne doivent être imprimés ou autrement reproduits sans son autorisation.
In compliance with the Canadian

Privacy Act some supporting forms may have been removed from this thesis.

While these forms may be included in the document page count, their removal does not represent any loss of content from the thesis.
Conformément à la loi canadienne sur la protection de la vie privée, quelques formulaires secondaires ont été enlevés de cette thèse.

Bien que ces formulaires aient inclus dans la pagination, il n'y aura aucun contenu manquant.

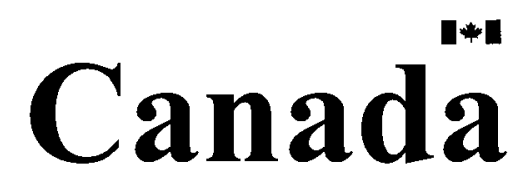




\section{Thesis Abstract}

The behavioural ecology of tropical birds is poorly studied. Many tropical birds perform vocal duets - the synchronization of male and female songs in a highly coordinated acoustic event. Although hypotheses have been proposed to explain the evolution and function of duets, duetting remains a poorly studied phenomenon. To explore the function of duetting, I investigated seasonal variation in duet singing of a neotropical songbird, the rufous-and-white wren (Thryothorus rufalbus). I found that duetting and individual singing strategies changed significantly with time of year and breeding stage. Female song and duetting peaked early in the year prior to breeding; male song and male duet responsiveness peaked with the onset of the rainy season when females became fertile. My results suggest that duets may be (1) cooperative displays used by pairs to jointly defend their territory and synchronize breeding activities, and (2) conflict displays used by males to mate guard their partners. 


\section{Co-Authorship Statement}

I certify that this thesis, and the research to which it refers, are the product of my own work, and that any ideas from the work of other people, published or otherwise, are fully acknowledged in accordance with the standard for referencing practices of the discipline. I acknowledge the input of my supervisor Dr. D. J. Mennill in the preparation of the manuscript (chapter 2) presented within which is written in manuscript format for submission to the journal of Animal Behaviour. I certify that the manuscripts were written by me and that the input of the co-author occurred during the development of the methodology, data collection from an earlier year (2004), and the editorial process. 
For Ruby and Patricia,

two of the best role models and 'adventurers' I know 


\section{Acknowledgments}

I would first and foremost like to thank my family who have always supported and encouraged me to seek my dreams, regardless of the path I needed to take. Their belief that I can accomplish whatever it is I put my mind to, is the rock that has seen me through all the ups and downs that come along the path with graduate school.

I owe a great deal to my field assistants David Bradley, Cheryl Calaustro, and Jason Mouland - all volunteers - for all their hard work, sweat, and persistence in the field. I wouldn't have such a fantastic data set without them. Thanks to Jessica Cuthbert and Roz Dakin for assisting with nest checks (i.e. carrying the ladder!). I also owe a great deal to the staff at Parque Nacional Santa Rosa in Costa Rica for making field work and living possible in Costa Rica, so hats off to: Roger Blanco, Maria Marta Chavarria, and the staff at Pocosol. Thanks to the community of international researchers in the park; especially the group from Cornell University living at Big Centeno, who provided assistance, support, and endless memories; life in Costa Rica would not have been the same without them.

I am indebted to Dan Mennill for choosing me above all others to be his first grad student, and for giving me the opportunity to work in Costa Rica on Rufous-and-white Wrens even though until our first meeting I didn't know what a 'duet' was, let alone that female birds could sing. I owe my academic success at Windsor and an exciting project to his guidance and support in the field and lab. Thanks also to Stephanie Doucet for her invaluable input on my project and for statistical support; as well as for creating an 
inviting environment at Windsor. Thanks to Sandi and Paui Mennill for being like an extended family; so welcoming and opening their home to the Mennill lab for retreats.

I thank the graduate students that have joined the Mennill and Doucet labs since my arrival, as well the other graduate students in the biology department for making my time at Windsor a memorable one. You know who you are.

Finally, I thank all the people and agencies who provided financial support for my research. I thank the Natural Sciences and Engineering Research Council of Canada (NSERC) for funding me directly and indirectly by supporting Daniel Mennill's research program. I thank the University of Windsor for supporting me directly with tuition scholarships during my tenure at the University, as well as financial support for attending conferences. I thank the Society of Canadian Ornithologists and Bird Studies Canada for a Fred Cooke Research Award. 


\section{Statement of Originality}

I certify that this thesis, and the research to which it refers, are the product of my own work, and that any ideas or quotations from the work of other people, published or otherwise, are fully acknowledged in accordance with the standard referencing practices of the discipline. I also certify that the work embodied within this thesis is the result of original research and has not been submitted for a higher degree to any other University or Institution. 


\section{Table of Contents}

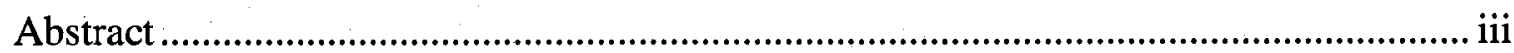

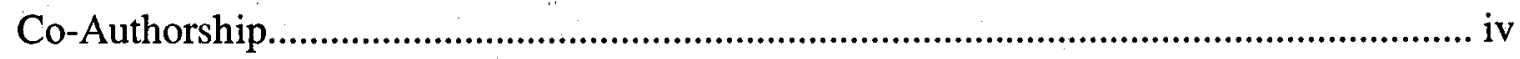

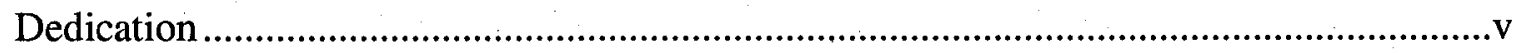

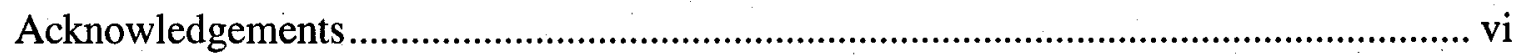

Statement of Originality...................................................................................... viii

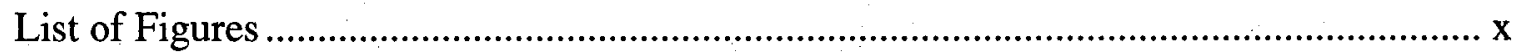

Chapter 1: General Introduction .......................................... 1

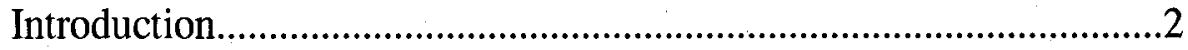

Male song - what do we know? ......................................................2

Female song and duetting - what do we know?.................................

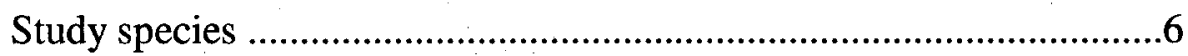

Rufous-and-White Wren song ...................................................

Conclusion .....................................................................................10

References........................................................................12

Chapter 2: Seasonal Variation in Duetting behaviour of Rufous-and-white Wrens (Thryothorus rufalbus) .................................................... 20

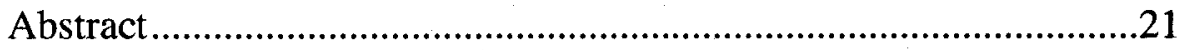

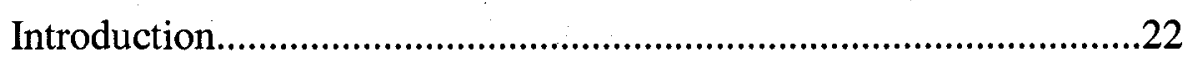

Methods ...............................................................................26

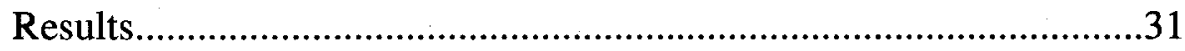

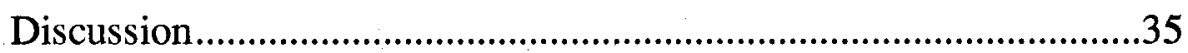

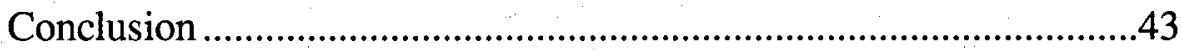

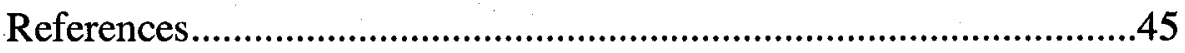

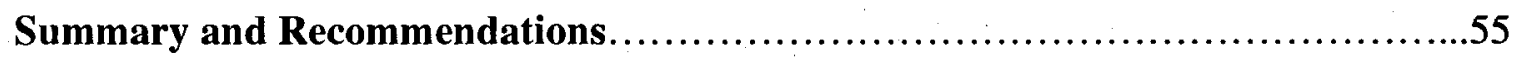

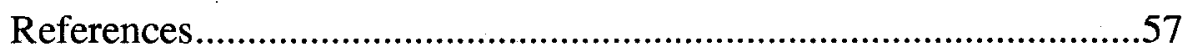

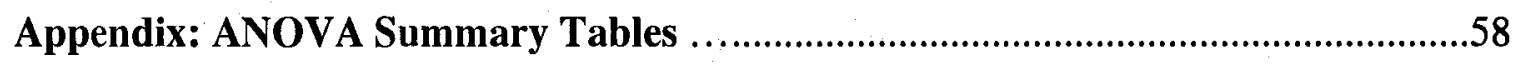

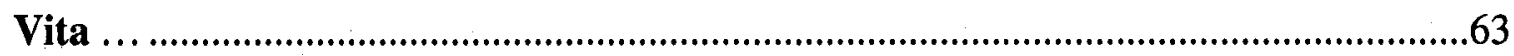




\section{List of Figures}

Figure 1.1. A spectrograph displaying the general structural characteristics of male and

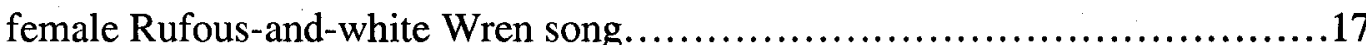

Figure 1.2. An example of song repertoires from male and female Rufous-and-white Wrens. .....

Figure 1.3. Spectrographs of male-created and female-created overlapping and alternating duets recorded from two separate pairs in April 2006.

Figure 2.1. Seasonal changes in average daily temperature and relative humidity in Parque National Santa Rosa, Costa Rica, in 2006 . .50

Figure 2.2. Variation in song output (per hour) of rufous-and-white wrens with time of year

Figure 2.3. Variation in song output (per hour) of rufous-and-white wrens with breeding stage

Figure 2.4. Variation in the proportion of song output per hour of female and male rufous-and-white wrens with breeding stage.

Figure 2.5. Variation in the male and female rufous-and-white wren duet responsiveness with breeding stage. .54 
Chapter 1

General introduction 


\section{Introduction}

Our understanding of bird song as a model of communication systems and animal behaviour is largely based on research that has been carried out in temperate regions (Morton 1996) where male birds are the primary singers. In tropical systems it is common for both the male and female of a species to sing (Slater \& Mann 2004) and in many species to form duets; highly coordinated, temporally precise, acoustic events that occur between two individuals, usually the male and female of a mated pair (Farabaugh 1982). Because of a temperate research bias bird song study has focused on understanding the evolution and function of male song (Morton 1996) and there is a large knowledge gap with respect to the role of female song, and the role and function of duetting in bird song communication and behaviour. My research aims to fill this gap through a focus on the behavioral ecology and evolutionary significance of vocal duetting in Neotropical songbirds.

\section{Male song - what do we know?}

Male song has been well studied and received much attention over the last 50 years (Slater 2003). Songs are loud and locatable signals providing information about sender identity, location, context, and signaller intention (Bradbury \& Vehrencamp 1998; Todt \& Naguib 2000). As a result it is now well recognized that song functions in both inter-and-intra sexual communication, by attracting mates and defending territories (Slater 2003).

Observational studies documenting cyclical patterns of song use and the effect of pairing on male singing behaviour provided the first indications of bird song function (reviewed in Catchpole \& Slater 1995). Observations that temperate male song birds start 
singing as they establish territories in the spring, with song rates peaking prior to females laying during the breeding season (e.g. Slagsvold 1977; D’Agincourt \& Falls 1983); or that in some species song rates decrease upon pairing (e.g. Catchpole 1973; Kelsey 1989) provided correlational evidence that song is important for attracting females and in maintaining territories. Experimental evidence from muting (e.g. Peek 1972; MacDonald 1989; Tomaszyck \& Adkins-Regan 2006), playback (e.g. Brooks \& Falls 1975; Falls \& D’Agincourt 1981; Otter et al. 1999; Mennill et al. 2002), and speaker replacement studies (e.g. Kreb et al. 1978; Yasukawa 1981 a, b; Eriksson \& Wallin 1986; Falls 1998) have conclusively shown that song is used to defend territories and attract mates.

With what is understood regarding male song today, researchers are able to examine how birds use song during interactions (e.g. different signalling strategies such as overlapping and matching) (e.g. Vehrencamp 2001; Mennill \& Ratcliffe 2004); how and if song types are used in different contexts (e.g. Kunc et al. 2005; Trillo \& Vehrencamp 2005); and how female mate choice influences the fine structural characteristics of song and male singing performance (e.g. Ballentine et al. 2004; Reid et al. 2004).

\section{Female song and duetting - what do we know?}

In comparison to male song, very little is known about female solo song. More has been addressed about vocal duetting in birds; however, both topics lag behind what is currently researched on song in male songbirds.

Female song is rare in temperate regions. Only in a few species such as the northern cardinal, (Cardinalis cardinalis, Ritchison 1986; Vondrasek 2006), the European robin (Erithacus rubecula, Kriner \& Schwabl 1987), and the superb-fairy wren 
(Malurus cyaneus, Cooney \& Cockburn 1995) is song relatively common. In most other temperate species, incluaing the song sparrow (Melospiza melodia, Arcese et al. 1988) or the white-crowned sparrow (Zonotrichia leucophrys, Baptista et al. 1993), female song is a rare occurrence. Early naturalists noted a seasonality or cyclical pattern of male song, and researchers who have documented female song (e.g. Cooney \& Cockburn 1995; Vondrasek 2006) found that it follows a similar cyclical pattern. In general, regardless of whether females are frequent singers, female song occurs more often early in the year prior to start of the breeding season (e.g. Baptista et al. 1993; Vondrasek 2006, but see Kriner \& Schwabl 1987). During the times when females sing, it appears to result from an increase in female aggression during the defence of a territory or resource (Langmore 1998) suggesting that the primary function of female song is resource defence. However, it is also possible that female song has been sexually selected and is used to attract mates (Langmore 1998).

In the tropics female song is much more common (Slater \& Mann 2004), yet the majority of research into female song in tropical regions focuses on duetting species and reasons for duets. Therefore, we still lack a good understanding of independent female song and the role it plays in sexual or natural selection (Slater \& Mann 2004). However, we are gaining a greater appreciation and understanding of the complex behaviour of duetting, and consequently a deeper understanding of some of the factors influencing female song.

Life history characteristics of tropical birds, such as year-round territoriality, long-term pair bonds and low adult mortality may support a convergence of male and female roles in the tropics (Morton 1996; Slater \& Mann 2004). In temperate regions, 
breeding seasons are short but predictable (Slater \& Mann 2004), creating a highly competitive breeding environment for temperate songbirds. As a result of these conditions, distinct sex-specific roles occur between male and female songbirds to ensure breeding success, such that males predominately defend territories and females lead parental care activities (Morton 1996). In the tropics, breeding seasons are long, their start is often unpredictable, and many species are year-round territory holders, which decreases the degree of intense competition for resources (Morton 1996; Slater \& Mann 2003). As a result, male and female roles appear to converge in the tropics with females singing possibly to defend territories, and males contributing a greater amount of time and energy to parental care activities (e.g. nest building, brooding; Morton 1996).

With what is known various hypotheses have been formulated to help explain the evolution and function of duetting with respect to differences in life history characteristics between temperate and tropical species, and whether they signal cooperation or conflict between the sexes (reviewed in Hall 2004). Four of the primary hypotheses are: (1) The Territory Defence Hypothesis which suggests that individuals join their partners' song to form duets as a collaborative display in defence of a resource against conspecific rivals (Seibt \& Wickler 1977); (2) The Mate Guarding Hypothesis which suggests that duetting is a non-cooperative display where individuals join in their partner's song to form a duet to prevent same-sex rivals from pairing with their partner (Stokes \& Williams 1968; Sonnenschein \& Reyer 1983; Levin 1996); (3) The Paternity Guarding Hypothesis which suggests that duetting is a non-cooperative display where males answer their partner's songs forming duets to prevent same-sex rivals from copulating with their partner (Sonnenschein \& Reyer 1983; Levin 1996); and (4) The 
Reproductive Synchrony Hypothesis which suggests that duetting is used by partners to help coordinate and initiate the timing of reproductive activities between a mated pair (Dilger 1953). To help explain the function of duetting in the tropics, I investigate the patterns of duetting with respect to time of year and breeding stage in rufous-and-white wrens, Thryothorus rufalbus, and consider these data with respect to the above hypotheses.

\section{Study species}

I use rufous-and-white wrens as a model system to investigate the function of duetting. Rufous-and-white wrens are oscine passerines in the family Troglodytidae (Stiles \& Skutch 1989). They are a medium sized (14 cm body length, Stiles \& Skutch 1989; 23-26 g, Mennill \& Vehrencamp 2005), resident neotropical songbird found from Mexico to Venezuela and Columbia in Central and South America (Stiles \& Skutch 1989). In our study area, the species inhabits moist regions of dry tropical forest (i.e. mature evergreen gallery forest or late-successional forests) (Stiles \& Skutch 1989), and defend their territories year-round.They are insectivores that predominately forage on the ground in the leaf litter or within a few meters of the ground in shrubby vegetation (Stiles \& Skutch 1989).

Male and female rufous-and-white wrens are monomorphic in appearance to human observers, however they are sexually dimorphic with respect to body measurements; males being larger and heavier than females (Mennill \& Vehrencamp 2005). Individuals form socially monogamous relationships, defending territories together and sharing all parental activities during the breeding season except incubation, which is solely done by females (pers. obs). It is unknown if rufous-and-white wrens are 
also genetically monogamous, although females have been observed making forays into neighbouring male territories prior to laying (pers. obs.). In general, mixed reproductive strategies are by far the most common reproductive strategy in songbirds (Griffiths et al. 2002).

Life span and pair duration of rufous-and-white wrens is unknown; however tropical species in general form longer duration pair-bonds (i.e. greater in length than one breeding season) (Slater \& Mann 2004) and have higher adult survival rates than temperate species (Skutch 1985; Martin 1996; Johnston et al. 1997; Peach et al. 2001). With respect to our study population, evidence suggests that the species is long-lived, and pairs form long-term pair bonds (i.e. greater than 1 year). For example, this population was first monitored in 2002, and in 2006 one mated pair from 2002 was still defending the same territory. My own recapture and re-sighting data show that survival rate of mated individuals between 2005 and 2006 was $76.7 \%$ (i.e. 23 out of 30 mated individuals from 2005 were still present in the study population at the beginning of the 2006 field season); $30-60 \%$ survival rates are more typical in temperate regions (reviewed in Karr et al. 1990).

Rufous-and-white wrens breed between April and August, timing the breeding season to coincide with onset of the rainy season. Like other species in the tropics, predation rates are high and nest success is low in our study population (Skutch 1985, Martin 1996). For example, in 2006 only 1 out of 12 nests from first clutches survived to produce fledglings (i.e. predation rate $91.7 \%$ ). Mated pairs attempt to re-nest following predation events; however the re-attempt rate is not known. Up to three re-nesting attempts has been observed for mated pairs in our study population by mid-July. It is 
unknown if rufous-and-white wrens attempt to breed a second time following a successful first clutch in one breeding season. Duration of post-fledging care is also unknown for this species; however long post-fledging care, delayed dispersal, and high fledging survival are assumed to be typical life-history characteristics of tropical birds (Skutch 1985; Martin 1996), and is supported in recent work (e.g. Geffen \& Yom-Tov 2000; Langen 2000; Russell 2000; Russell et al. 2004; Schaefer et al. 2004).

\section{Rufous-and-white wren song}

Male and female rufous-and-white wrens sing solo songs, and combine their solo songs together forming duets. The structure of both male and female solo song follows a similar pattern consisting of introductory syllables, a middle trill section, and a terminal syllable (Fig. 1.1) (Mennill \& Vehrencamp 2005). However, male and female song differs with respect to fine structural details. For example, trill length is significantly longer and frequency characteristics are significantly lower in male solo than female solo song (Mennill \& Vehrencamp 2005). These differences allow practiced human listeners to distinguish between males and females in the field.

Males also sing more often than females, singing $93 \%$ of the songs recorded for a pair (Mennill \& Vehrencamp 2005). Males and females have repertoires of distinct song types (Fig. 1.2), with males having significantly larger repertoires on average than females $(10.8 \pm 0.7$ song types versus $8.5 \pm 0.7)$ (Mennill \& Vehrencamp 2005). Individuals use a repeat-mode singing strategy, repeating the same song type many times before switching to a different song type (Mennill \& Vehrencamp 2005). Male rufousand-white wrens repeat the same song type more times than females do in a song bout 
before switching to a different one $(11.0 \pm 0.9$ times versus $2.7 \pm 0.9)$ (Mennill \& Vehrencamp 2005).

With respect to song types, individuals (males and females) in a population share at least one song type with a same-sexed neighbour; males generally share more song types than females (Mennill and Vehrencamp 2005). Some song types are sex-specific, while others are shared between the sexes (Mennill \& Vehrencamp 2005). While little is known about song learning in this species in particular and in females more generally, this pattern of song sharing suggests that some songs may be learned from tutors of either sex, but other songs must be learned from tutors of the same sex.

Males and females create duets by responding to their partner's solo song. Both males and females create duets, although female's create the majority of duets (i.e. join their partner's song more often) in this species (i.e. $73.0 \pm 2.0 \%$ ) (Mennill \& Vehrencamp 2005). In other species (e.g. Plain Wren, Thryothorus modestus zeledoni, Mann et al. 2003), duets are highly precise acoustic events following a specific malefemale alternating pattern. Rufous-and-white wrens do not perform such precisely timed alternating duets, instead the duet creator either overlaps their partner's song or follows their partner's song (Mennill \& Vehrencamp 2005) (Fig. 1.3). Mated pairs combine their solo songs non-randomly when creating duets, resulting in pair-specific duet types and duet repertoires (Mennill \& Vehrencamp 2005). The significance between the different styles of duetting and the function of duet repertoires is still largely unknown and untested. 


\section{Conclusion}

Our understanding of bird song as a model of communication systems and animal behaviour is biased towards findings and studies that have assessed the function and evolution of song in temperate regions (Morton 1996, Slater 2003). Male songbirds are the primary singers in temperate regions; however, in tropical regions it is common for both males and females of a species to sing, and within many species for mated pairs to combine solo songs creating an acoustic event called a duet (Farabaugh 1982). To date, female song and duetting have been grossly understudied and as a result there is a large knowledge gap with respect to the function of duetting in bird song communication.

From temperate research, we have a fairly good understanding of the seasonal changes in song function and we know that male song has two primary functions - mate attraction and territory defence (Catchpole \& Slater 1995; Searcy \& Nowicki 2000; Collins 2004). With respect to duetting, seasonal changes in song use and the role song plays in communication for duetting species is relatively unknown. The rufous-and-white wren is a model study species to address the question of seasonal variation and duet function because they are non-migratory, they are year-round territory holders, and both the male and female have distinct song repertoires consisting of between 6-14 song types (Mennill \& Vehrencamp 2005). Mated pairs combine their songs into distinct duet types, where particular song types from the male and female are combined together more often than is predicted by chance (Mennill \& Vehrencamp 2005), which may imply that certain songs are associated with different contexts or functions. While it is recognized that duetting has multiple functions (Slater \& Mann 2004; Hall 2004), without an understanding of how song use changes from the non-breeding season and throughout 
Chapter 1 - General Introduction

different stages of the breeding season, we will never be able to fully grasp the significance of duetting for tropical species. 


\section{References}

Arcese, P., Stoddard, P. K. \& Hiebert, S. M. 1988. The form and function of song in' female song sparrows. Condor, 90, 44-50.

Ballentine, B., Hyman, J. \& Nowicki, S. 2004. Vocal performance influences female response to male bird song: an experimental test. Behavioural Ecology, 15, 163168.

Bradbury, J. W. \& Vehrencamp, S. 1998. Principles of Animal Communication. USA: Sinauer Associates.

Brooks, R. J. \& Falls, J. B. 1975. Individual recognition by song in white-throated sparrows. 1. Discrimination of songs of neighbors and strangers. Canadian Journal of Zoology, 53, 879-888.

Catchpole, C. K. 1973. Variation in the song of the great reed warbler Acrocephalus arundinaceus in relation to mate attraction and territorial defence. Animal Behaviour, 31, 1217-1225.

Catchpole, C. K. \& Slater, P. J. B. 1995. Bird song: Biological Themes and Variations. Cambridge: Cambridge University Press.

Collins, S. 2004. Vocal fighting and flirting: the functions of birdsong. In: Nature's Music: The Science of Birdsong (Ed. by P. Marler \& H. Slabbekoorn), pp.39-79. California: Elsevier Academic Press.

Cooney, R. \& Cockburn, A. 1995. Territorial defence is the major function of female song in the superb fairy-wren, Malurus cyaneus. Animal Behaviour, 49, 1635 1647.

D'Agincourt, L. G. \& Falls, J. B. 1983. Variation in repertoire use of eastern meadowlark. Canadian Journal of Zoology, 61, 1086-1093.

Dilger, W. C. 1953. Duetting in the crimson-breasted barbet. Condor, 55, 220-221.

Falls, J. B. 1988. Does song deter territorial intrusions in white-throated sparrows (Zonotrichia albicollis). Canadian Journal of Zoology, 66, 206-211.

Falls, J. B. \& D'A gincourt, L. G. 1981. A comparison of neighbor-stranger discrimination in eastern and western meadowlarks. Canadian Journal of Zoology, 59, 2380-2385.

Farabaugh, S. M. 1982. The ecological and social significance of duetting. In: Acoustic Communication in Birds. Vol. 2 (Ed. by D. E. Kroodsma \& E. H. Miller), pp. 85124. New York: Academic Press. 
Eriksson, D. \& Wallin, L. 1986. Male bird song attracts females - a field experiment. Behavioural Ecology \& Sociobiology, 19, 297-299.

Geffen, E. \& Yom-Tov, Y. 2000. Are incubation and fledging periods longer in the tropics? Jourinal of Animal Ecology, 69, 59-73.

Griffith, S. C., Owens, I. P. F. \& Thuman, K. A. 2002. Extra pair paternity in birds: a review of interspecific variation and adaptive function. Molecular Ecology, 11, 2195-2212.

Hall, M. L. 2004. A review of hypotheses for the functions of avian duetting. Behavioral Ecology and Sociobiology, 55, 415-430.

Johnston, J. P., Peach, W. J., Gregory, R. D. \& White, S. A. 1997. Survival rates of tropical and temperate passerines: a Trinidadian perspective. American Naturalist, 150, 771-789.

Karr, J. R., Nichols, J. D., Klimkiewicz, M. K. \& Brawn, J. D. 1990. Survival rates of birds in tropical and temperate forests: will dogma survive? American Naturalist, 136, 277-291.

Kelsey, M. G. 1989. A comparison of the song and territorial behaviour of a long-distant migrant, the marsh warbler Acrocephalus palustris, in summer and winter. Ibis, 131, 403-414.

Kreb, J. R., Ashcroft, R. \& Webber, M. 1978. Song repertoires and territory defence in great tit. Nature, 271, 539-542.

Kriner, E. \& Schwabl, H. 1991. Control of winter song and territorial aggression of female robins (Erithacus rubecula) by testosterone. Ethology, 87, 37-44.

Kunc, H. P., Amrhein, V. \& Naguib, M. 2005. Acoustic features of song categories and their possible implications for communication in the common nightingale (Luscinia megarhynchos). Behaviour, 142, 1077-1091.

Langen, T. K. 2000. Prolonged offspring dependence and cooperative breeding in birds. Behavioural Ecology, 11, 367-377.

Langmore, N. E. 1998. Functions of duet and solo songs of female birds. Trends in Ecology \& Evolution, 13, 136-140.

Levin, R. N. 1996. Song behaviour and reproductive strategies in a duetting wren, Thryothorus nigricapillus: II. Playback experiments. Animal Behaviour, 52, $1107-$ 1117.

Mann, N. I., Marshall-Ball, L. \& Slater, P. J. B. 2003. The complex song duet of the Plain Wren. Condor, 105, 672-682. 
Martin, T. E. 1996. Life-history evolution in tropical and south temperate birds: what do we really know? Journal of Avian Biology, 27, 263-272.

Mennill, D. J. \& Ratcliffe, L. M. 2004. Overlapping and matching in the song contests of black-capped chickadees. Animal Behaviour, 67, 441-450.

Mennill, D. J., \& Verehncamp, S. L. 2005. Sex differences in the singing and duetting behaviour of neotropical rufous-and-white wrens (Thryothorus rufalbus). Auk, 122, 175-186.

Mennill, D. J., Ratcliffe, L. M. \& Boag, P. T. 2002. Female eavesdropping on male song contests in songbirds. Science, 296, 873.

McDonald, M. V. 1989. Functions of song in Scotts Seaside Sparrow, Ammodramusmaritimus-peninsulae. Animal Behaviour, 38, 468-485.

Morton, E. S. 1996. A comparison of vocal behaviour among tropical and temperate Passerine birds. In: Ecology and Evolution of Acoustic Communication in Birds (Ed. by D. E. Kroodsma \& E. H. Miller), pp. 258-268. New York: Cornell University Press.

Otter, K., Chruszez, B. \& Ratcliffe, L. 1997. Honest advertisement and song output during the dawn chorus of black-capped chickadess. Behavioural Ecology \& Sociobiology, 8, 167-173.

Otter, K., McGregor, P. K., Terry, A. M. R., Burford, F. R. L, Peake, T. M. \& Dabelsteen, T. 1999. Do female great tits (Parus major) assess males by eavesdropping? A field study using interactive song playback. Proceedings of the Royal Society of London Series B, 266, 1305-1309.

Peach, W. J., Hanmer, D. B. \& Oatley, T. B. 2001. Do southern African songbirds live longer than their European counterparts? Oikos, 93, 235-249.

Peek, F. W. 1972. An experimental study of territorial function of vocal and visual display in male red-winged blackbird (Agelaius phoeniceus). Animal Behaviour, 20, 112-118.

Reid, J. M., Arcese, P., Cassidy, A. L. E. V., Hieberts, S. M., Smith, J. N. M., Stoddard, P. K., Marr, A. B. \& Keller, L. F. 2004. Song repertoire size predicts initial mating success in male song sparrows, Melospiza melodia. Animal Behaviour, 68, 1055-1063.

Ritchison, G. 1986. The singing behavior of female northern cardinals. Condor, 88, 156159.

Russel, E. M. 2000. Avian life-histories: is extended parental care the southern secret? Emu, 100, 377-399. 
Russell, E. M., Yom-Tov, Y. \& Geffen, E. 2004. Extended parental care and delayed dispersal: northern, tropical, and southern passerines compared. Behavioral Ecology, 15, 831-838.

Schaefer, H. C., Eshiamawata, G. W., Munyekenye, F. B. \& Böhning-Gaese, K. 2004. Life-history of two African Sylvia warblers: low annual fecundity and long post-fledging care. Ibis, 146, 427-437.

Searcy, W. A. \& Nowicki, S. 2000. Male-male competition and female choice in the evolution of vocal signaling. In: Animal Signals: Signaling and Signal Design in Animal Communication (Ed. by Y. Espmark, T. Amundesen \& G. Rosensqvist), pp. 301-315. Norway: Tapir Academic Press.

Seibt, U. \& Wickler, W. 1977. Duettieren als Revier-Anzeige bei Vogeln. Zeitschrift für Tierpsychologie, 43, 180-187.

Skutch, A. F. 1985. Clutch size, nesting success, and predation on nests of Neotropical birds, reviewed. Ornithological Monographs, 36, 575-594.

Slater, P. J. B. 2003. Fifty years of bird song research: a case study in animal behaviour. Animal Behaviour, 65, 633-639.

Slater, P. J. B. \& Mann, N. I. 2004. Why do females of many bird species sing in the tropics? Journal of Avian Biology, 35, 289-294.

Slagsvold, T. 1977. Bird song activity in relation to breeding cycle, spring weather, and environmental phenology. Ornis Scandinavica, 8, 197-222.

Sonnenschein, E. \& Reyer, H. U. 1983. Mate-guarding and other functions of antiphonal duets in the slate-coloured boubou (Laniarus funebris). Zeitschrift für Tierpsychologie, 63, 112-140.

Stiles, F. G. \& Skutch A. F. 1989. A guide to the birds of Costa Rica. Cornell University Press, Ithaca, N.Y.

Stokes, A. W. \& Williams, H. W. 1968. Antiphonal calling in quail. Auk, 85, 83-89.

Tingay, S. 1974. Antiphonal song of the magpie lark. Emu, 74, 11-17.

Trillo, P. A. \& Vehrencamp, S. L. 2005. Song types and their structural features associated with specific contexts in the banded wren. Animal Behaviour, 70, 921935.

Tomaszycki, M. L, \& Adkins-Regan, E. 2006. Experimental alteration of male song quality and output affects female mate choice and pair bond formation in zebra finches. Animal Behaviour, 70, 785-794. 
Vehrencamp, S. L. 2001. Is song-type matching a conventional signal of aggressive intentions? Proceedings of the Royal Society of London, Series B, 268, 16371642 .

Vondrasek, J. R. 2006. Social factors affect the singing rates of female northern cardinals Cardinalis cardinalis. Journal of Avian Biology, 37, 52-57.

Yasukawa, K. 1981a. Song and territory defence in the Red-winged Blackbird. $A u k, 98$, 185-187.

Yasukawa, K. 1981b. Song repertoires in the red-wingned blackbird (Agelaius phoeniceus): A test of the Beau Geste hypothesis. Animal Behaviour, 29, 114125. 


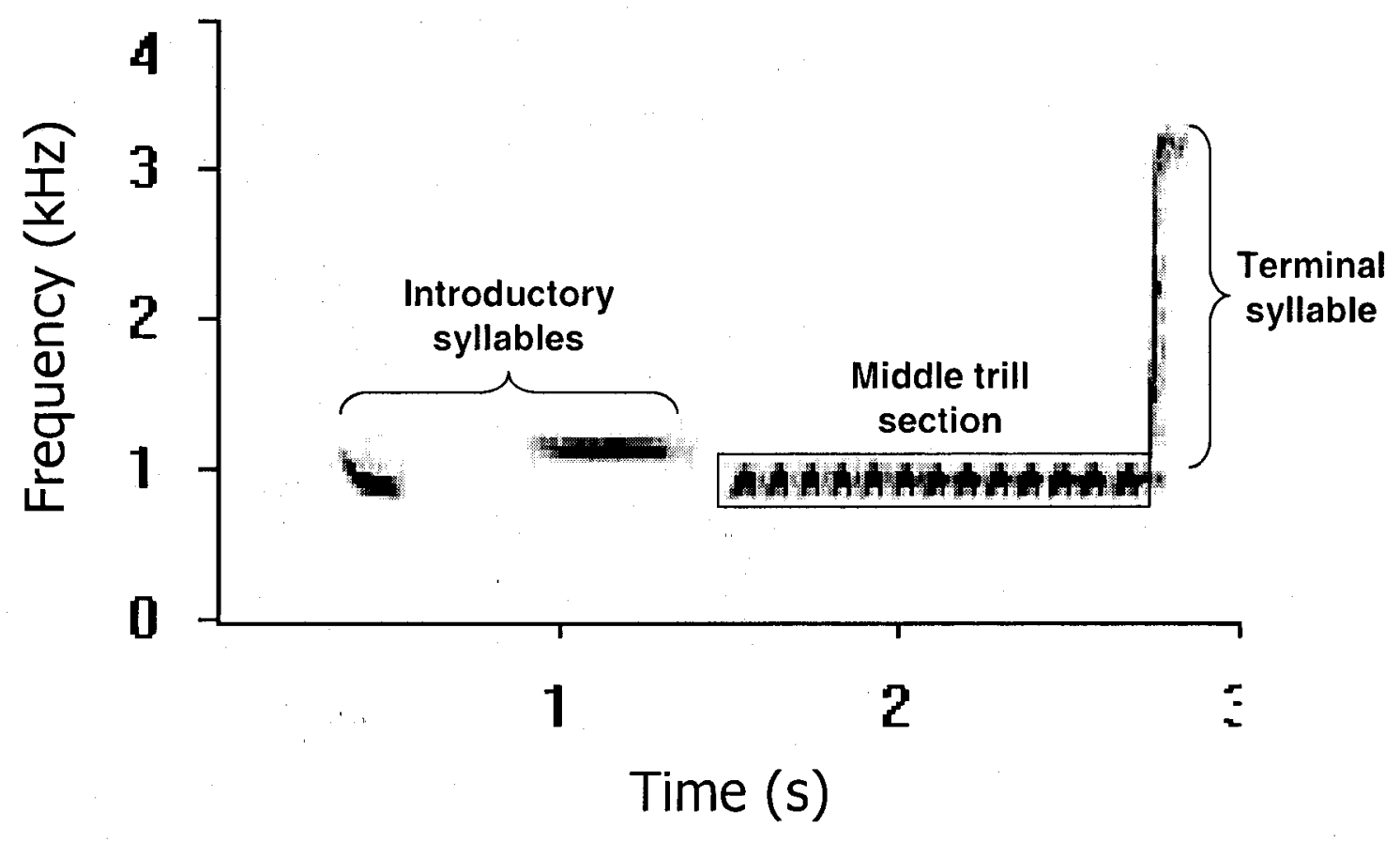

Figure 1.1 A spectrograph displaying the general structural characteristics of male and female Rufous-and-white Wren song. 
(a)

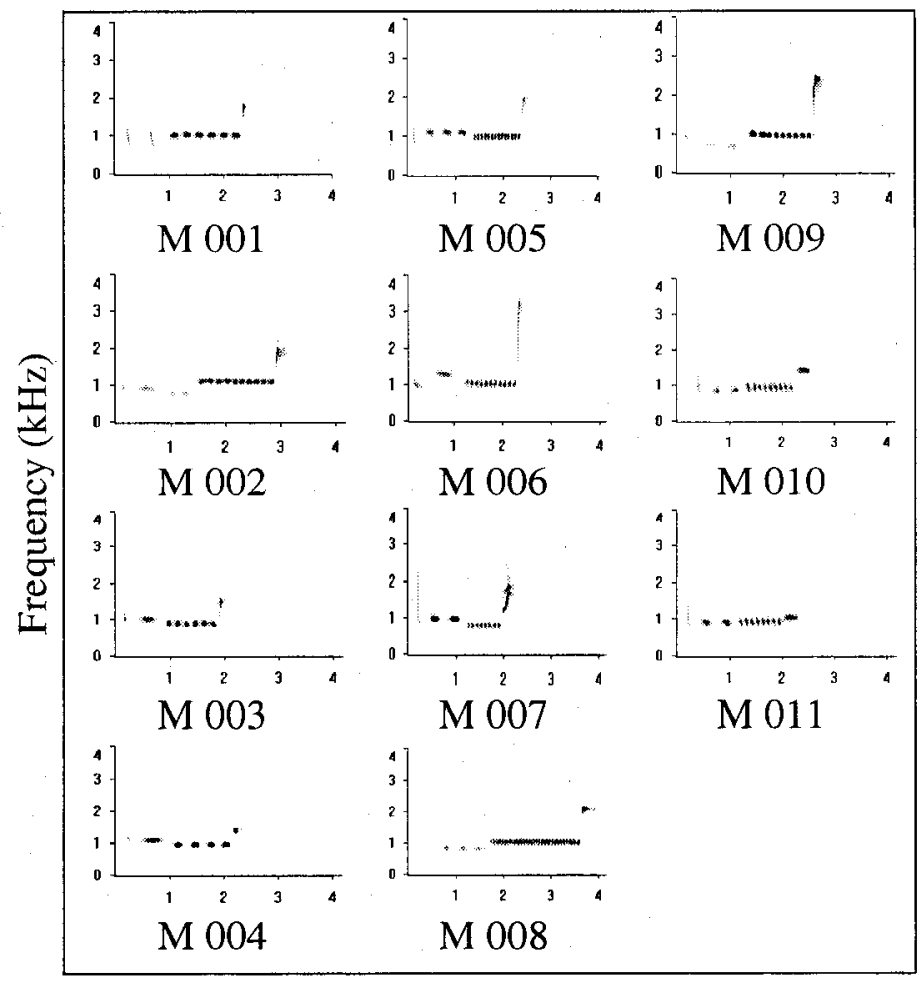

Time (s) (b)

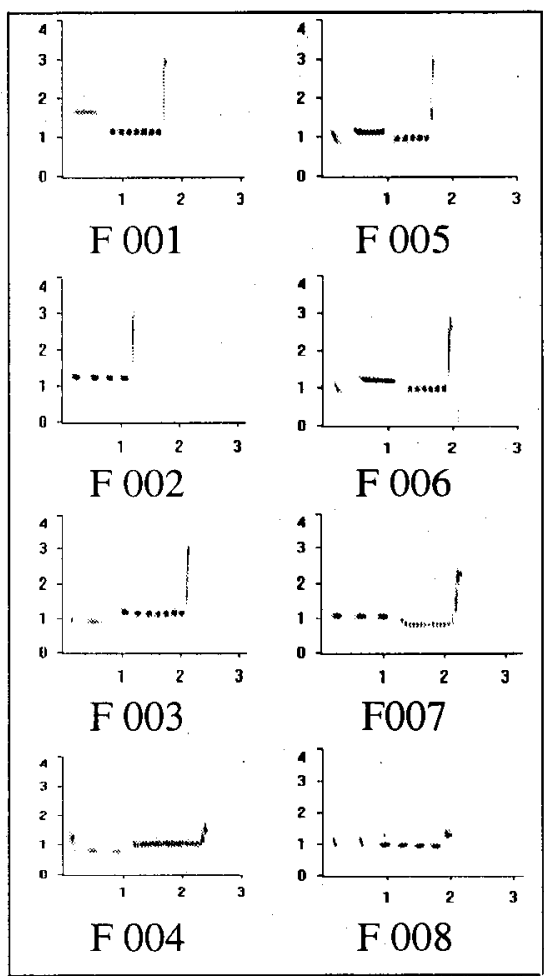

Time (s)

Figure 1.2 An example of song repertoires from male and female Rufous-and-white Wrens. (a) Represents a male repertoire consisting of 11 song types, (b) represents a female repertoire consisting of 8 song types. Both male and female repertoires are based on recordings collected during a pilot study in 2005 . 
(a)

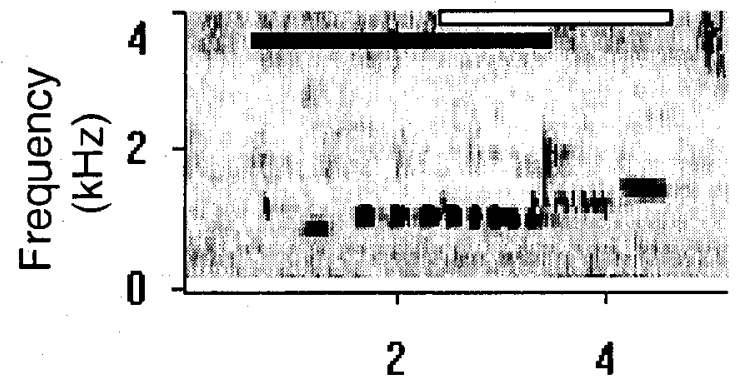

(c)

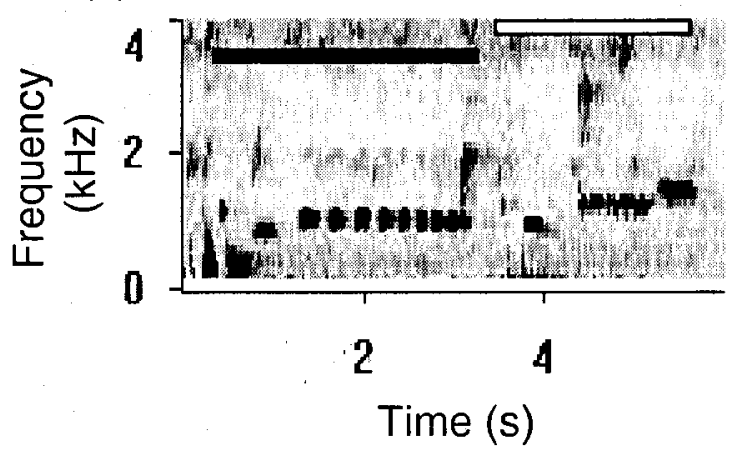

(b)

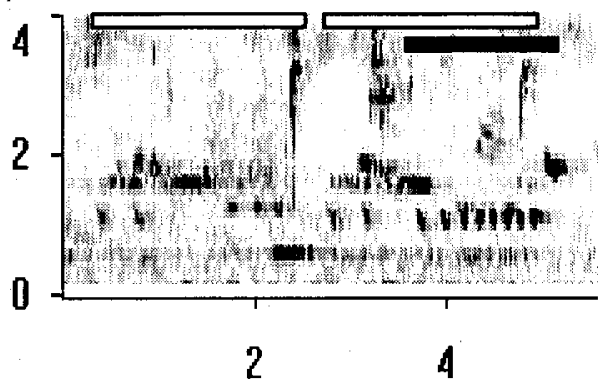

(d)

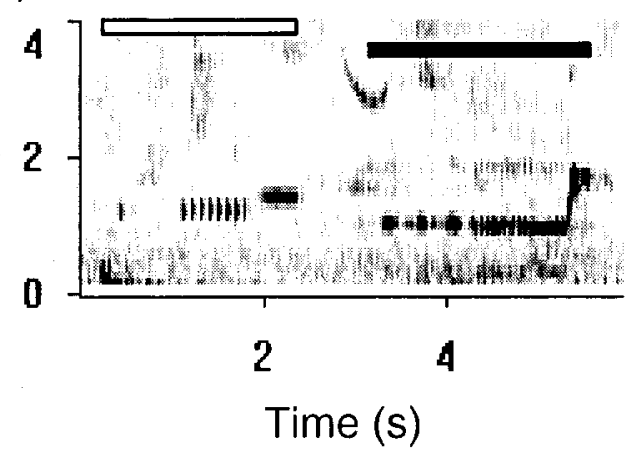

Figure 1.3 Spectrographs of male- and female-created, overlapping and alternating duets recorded from two separate pairs in April 2006. (a) A female-created overlapping duet, (b) a male-created overlapping duet, (c) a female-created non-overlapping or alternating duet, and (d) a male-created alternating duet. Note: (a) \& (c) were recorded during a duet bout and are the same duet type (i.e. consist of the same male and female song types). 
Chapter 2

Seasonal variation in the duetting behaviour of Rufous-and-white Wrens

(Thryothorus rufalbus) 


\section{Abstract}

Seasonal patterns of song use in temperate species have been well documented and have contributed to our understanding of the dual functions of bird song in mate choice and territory defence. For species in which females sing and mated pairs combine their songs into acoustic duets, the relationship between the function of song and season is still poorly understood. Various hypotheses have been proposed to explain the function of duets and female song, yet few studies have addressed how these vocalizations vary seasonally. We examined how singing behaviour changes in relation to time of year and breeding stage in a population of rufous-and-white wrens (Thryothorus rufalbus) in Costa Rica. We recorded a colour-marked population of birds over an extended time period encompassing multiple breeding stages. We interpret data based on (1) male and female independent singing strategies and (2) duetting strategies. Across all time frames pairs produce more solo songs than duets and males always sing at higher rates than females, regardless of time of year or breeding stage. However, males and females have divergent seasonal patterns of singing. Female song is highest early in the year during the prebreeding season and females drive the observed temporal pattern of temporal duetting. Male solo song peaks at the onset of the rainy season when females are fertile and males join more of their partner's song during this stage. Changes observed in duet behaviour with time of year and breeding stage in rufous-and-white wrens suggest that duets serve multiple functions. Our results suggest that early in the year duets probably represent cooperative displays, functioning in joint territory defence and in the coordination of breeding activities. When females are fertile, duets may represent conflict between the sexes, with duets likely functioning as a paternity guard. 


\section{Introduction}

Seasonal patterns of variation in animal behaviours provide insight into the function of those behaviours. For example, in temperate songbirds studies documenting annual variation in male vocal behaviour provided some of the first evidence that song acts as a multifunctional signal in both mate attraction and territory defence (e.g. Catchpole 1973; Slagsvold 1977; Logan 1983; Lampe \& Espmark 1987). Signals that are less prevalent, such as female song (Langmore 1998) or vocal duets (Hall 2004) are still understudied and poorly understood. Even less is known about how duets or female song are used during different stages or at different times of the year. To date, more than 222 mainly tropical species are known to duet (Farabaugh 1982), occurring in phylogenetically distinct groups (Farabaugh 1982; Geissmann 2002). This suggests that selection for duetting behaviour is strong in the tropics; yet the function of duets and the relationship between duetting and breeding behaviour are still unclear.

Duets occur when males and females vocalize together in a highly coordinated fashion (Farabaugh 1982; Hall 2004). Hypotheses for the function of vocal duets fall into two broad categories based on: (1) intended receivers of the signals that comprise the duet and (2) whether duets signify cooperative displays or occur as a result of conflict between individuals (Hall 2004). Duets result from individual singing strategies and are created when the second individual responds to the duet initiator; otherwise the initial individual continues to sing solo songs (Hall 2004). As a result, we can generate predictions suited for assessing changes over time based on duet rates, changes in responsiveness (i.e. number of partner's songs that the mate answers to create a duet), or changes in proportion of duets created by each partner to assess duet function. For 
example, if duetting acts as a paternity guard when females are fertile (Sonnenschein \& Reyer 1983), as is a suggested function of song for some temperate songbirds (Moller 1998), males should be more responsive to their partners song by creating more duets (i.e. females should initiate more duets) during this stage (Levin 1996; Hall 2004).

Studies assessing the function and adaptive significance of duetting behaviour have largely used an experimental approach, simulating territorial intrusions using playback to test hypotheses and evaluate duet function (e.g. Levin 1996; Hall 2000; Seddon et al. 2002; Mennill 2006). Playback studies, however, only capture a moment in time and few studies consider the effect of different contexts (e.g. fertile versus nonfertile contexts) or time of year (e.g. dry versus rainy seasons) on behaviour (Hall 2004). It is important to analyse both time of year and breeding stage changes in singing behaviour, because both temperate and tropical species coordinate breeding to occur when food resources are available (Dawson et al 2001). This period in general is predictable for temperate species and unpredictable for tropical species, because the onset of the rainy season in the tropics may vary significantly from year to year (Hau 2000; Dawson et al. 2001; Hau 2001; Slater \& Mann 2004). Therefore changes in singing behaviour with time of year in tropical species may shed significant insight into song function.

Both context and time of year are known to influence vocalizations of male and female temperate birds, reflecting the changing role that song plays in communication. For example, male blue grosbeaks, Guiraca caerulea, increase their song complexity, dawn chorus song rate, and number of song bouts during their female's fertile period (Ballentine et al. 2003), suggesting that song functions as an assessment signal during 
this stage (Ballentine et al. 2003). Studies documenting female song have found that females vocalize early in the year prior to nest-building, suggesting that the primary function of song for females is territory or resource defence (e.g. northern cardinals, Cardinalis cardinalis, Ritchison 1986; Vondrasek 2006; song sparrows, Melospiza melodia, Arcese et al. 1988; superb fairy wrens, Malurus cyaneus, Cooney \& Cockburn 1995).

Studies evaluating duet function using playback have documented increased levels of duetting and aggressive responses in many species (e.g. Levin 1996b; Hall 2000; Logue \& Gammon 2004; Mennill 2006; Rogers et al. 2007), suggesting that duets function in joint territory defence. In addition, differential responses by individual male and females to same-sexed versus opposite-sexed intruders have also been observed and suggest that duets have a mate defence function (e.g. tropical boubou, Laniarius aethipicus, Grafe \& Bitz 2004; rufous-and-white wren, Thryothorus rufalbus, Mennill 2006; eastern whipbird, Psophodes olivaceus, Rogers et al. 2007).

Two recent studies on duetting have repeated simulated intrusions at different breeding stages or times of year. Hall (2000) repeated duet and solo playback trials on magpie-larks, Grallina cyanoleuca, during the non-breeding and pre-breeding season and found that response rates measured did not differ significantly between seasons, which she proposed was a function of year-round territoriality of this species. Fedy \& Stutchbury (2005) performed playback to white-bellied antbirds, Myrmeciza longipes, during the dry (non-breeding) and rainy (breeding) seasons and found that birds responded more aggressively to simulated intrusion during the dry season, suggesting that time of year or breeding stage influences duet behaviour. Overall, few studies have 
examined the interplay of time of year or breeding stage on duetting behaviour and individual singing strategies of males and females. As a result, little is known about how singing strategies change in duetting species or what roles males and females play in inter- and-intra sexual communications.

In this study, we investigate the singing strategies of rufous-and-white wrens with respect to time of year and breeding stage. Rufous-and-white wrens are socially monogamous resident neotropical songbirds found from Mexico to Columbia and Venezuela (Stiles \& Skutch 1989). Rufous-and-white wrens hold year-round territories and during the breeding season males and females share parental duties (nest building and feeding duties, but not incubation or brooding) (pers. obs). Males and females have song repertoires, sing independent solo songs, and pairs perform coordinated overlapping or alternating duets (Mennill \& Vehrencamp 2005). Both sexes create duets (i.e. respond to their partner's solos), although females create more duets on average than males (Mennill and Vehrencamp 2005). Responses to duet playback suggest that duets may function as a cooperative territorial defence display and as a mate or paternity guarding display by males (Mennill 2006).

The goal of this study is to describe annual and breeding stage patterns of rufousand-white wren singing behaviour using a series of dawn chorus recordings collected from a colour-marked population over an extended time period and encompassing multiple breeding stages. We examine song function based on the relative use of duets and solo songs, and the proportion of male versus female contributions to song with respect to time of year and breeding stage. 


\section{Methods}

\section{Study Species and Population}

We studied a population of rufous-and-white wrens in the humid forests of Parque Nacional Santa Rosa in the Santa Rosa sector of the Area de Conservacion Guanacaste, Costa Rica $\left(10^{\circ} 40^{\prime} \mathrm{N}, 85^{\circ} 30^{\prime} \mathrm{W}\right)$. From 2004 through 2006 we monitored 15-20 territories per year. Birds were captured in mist nets using passive netting or brief periods of song playback. Each individual was given a unique combination of three plastic colour bands and one numbered aluminum band, and standard morphometric measurements were taken. Males and females were easily distinguished on the basis of morphometric measurements (Mennill \& Vehrencamp 2005), brood patches, and/or behavioural observations.

\section{Sound Recordings}

We used Marantz digital recorders (model PMD-670 or PMD-660) and Sennheiser directional microphones (model MKH70 or ME67) to record all vocalizations produced by pairs during focal recordings made from March to July of 2004 to 2006. This time period encompasses the end of the dry season (mid-December to May) and the beginning of the rainy season for the Pacific coast of Costa Rica. Each year we recorded the date of the first prolonged rainfall marking the start of the rainy season. In 2006, we also deployed a temperature and humidity data logger (model: Onset Hobo Pro Series) to document the transition from dry to wet season; the data logger recorded temperature $\left({ }^{\circ} \mathrm{C}\right)$ and relative humidity (\%) every half hour throughout the entire field season. 
We studied time of year and breeding stage changes in the singing behaviour of rufous-and-white wrens by recording focal pairs $(\mathrm{N}=17$ unique pairs or 34 unique individuals) cyclically throughout the field season, revisiting each pair approximately every 10-15 days. To monitor how singing behaviour changed with time of year, we attempted to record each pair during each of the following time periods: (1) late March (16-31), (2) early April (1-15), (3) late April (16-30), (4) early May (1-15), (5) late May (16-31), (6) early June (1-15), (7) late June (16-30), and (8) early July (1-15).

To monitor how singing behaviour changed with breeding stage, we attempted to record all pairs at least once during each of the following breeding cycles: (1) prebreeding period (period before any nest-building activity was observed; $\mathrm{N}=12$; recording range: March 23 to May 7), (2) nest-building period (including re-nesting attempts following nest failure; $N=17$; recording range: April 14 to June 17), (3) female fertile period (defined as the period of four days prior to laying and the first two days of egg laying; this period corresponds to the period when copulations were observed; $\mathrm{N}=$ 11; recording range: April 27 to July 9), (4) incubation perjod ( $\mathrm{N}=17$; recording range: May 4 to July 13), (5) nestling period ( $N=7$; recording range: May 18 to July 16), (6) fledgling period (after young had left the nest but were still accompanied by parents; $\mathrm{N}=1$; July 1), and (7) post-predation events (defined as the period following nest predation, but before the pair began to construct a new nest; $\mathrm{N}=3$; recording range: May 10 to June 11$)$.

Focal recordings took place over a two-hour time period between 0500 and 0700 hours encompassing the dawn chorus, a time when rufous-and-white wren is most common (Mennill \& Vehrencamp 2005). We recorded 115 focal recordings, collecting 
over $201 \mathrm{~h}$ of recordings from the 17 pairs. Continuous recording sessions lasted $104 \pm$ $1.74 \mathrm{~m}$ (range $32-126 \mathrm{~m}$ ), and in total each pair was recorded for an average of $11.88 \pm$ $0.002 \mathrm{~h}$. During focal recording sessions, the recordist followed the focal male and female around their territory. At the beginning and end of each focal recording, the recordist stated the time, date, and breeding stage. In addition, the recordist dictated the singers' identities, location within the territory, type of song (solo or duet), and in the case of a duet which sex initiated the duet (i.e. sang first) whenever this information was known. Male and female rufous-and-white wren songs have distinct frequency and fine structural characteristics (Mennill \& Vehrencamp 2005), therefore experienced listeners are able to identity the sex of the singer based on song characteristics. Visual confirmation of the individual(s) being recorded was sought whenever possible.

To determine the breeding stage of each pair, from 0700 to 1100 hours we carried out behavioural observations and performed nest checks. Whenever possible, we observed each pair for one hour on the day prior to collecting a focal recording. In addition, nests were checked for eggs or, when active, observed during one hour nest watches every three days to monitor for predation events and to determine the female's fertile period.

\section{Song Analysis}

We visualized all focal recordings as continuous spectrographs using SYRINXPC sound analysis software (J. Burt, Seattle, Washington), and for each recording we tabulated the following characteristics: (1) time of first song, (2) time of last recorded song, (3) time at end of recording, (4) total number of songs produced, (5) sex of the 
singer, (6) whether the song was a solo or pait of a duet, (7) the song type, and ( 8 ) for songs produced during a duet, who the duet-initiator was (i.e. which bird vocalized first in a duet; e.g. male-initiated duet, consists of male song followed by a female song). We calculated the independent song rate (per hour) for both individuals as well as the duet and solo rate (per hour) for the pair. For each individual, we calculated independent song rate as the sum of all duets where that individual sang first and all solo songs for that individual (i.e. times when an individual is singing autonomously and may or may not be joined by its partner).

We quantified the responsiveness of individuals to their partner's song, as the proportion of their partner's total song output that they answered to create a duet. For example, female responsiveness was calculated as total male-initiated duets divided by the sum of total male-initiated duets and total male solos (Hall 2006; Mennill 2006). As a comparison we also calculated the proportion of total songs that pairs sung as duets or solos, and the proportion of duets created by males and females to further examine the role each sex plays in shaping the patterns of duetting in this species.

\section{Statistical Analysis}

We used mixed-model ANOVA to evaluate (1) combined duet and solo rates for pairs, (2) independent song and duet rates for individuals, (3) proportion of duet and solo songs, (4) the proportion of male and female created duets sung, and (5) duet responsiveness for males and females. We used this approach because our data set lacked independence due to repeated sampling and our sample sizes were unbalanced. However, this approach enabled us to incorporate both fixed and random effects in the analysis so 
that the interdependence of data collected from the same bird or pair (random effect) is taken into account during the assessment of the fixed effects (dependant variables). For all models, variance associated with random effects was estimated using expected means squares (EMS) method and fixed effects were estimated using standard least squares (SLS).

Two separate models were fitted for each dependent variable to test the effect of (1) time of year and (2) breeding stage (independent variables) on singing behaviour. Models evaluating time of year were unrestricted by breeding stage and models evaluating breeding stage were unrestricted by time of year. Song rate variables were normalized with a square root transformation and proportional variables were normalized with an arcsine transformed to improve normality and allow for parametric analysis. As expected, pair or individual (male or female) effects for most models was highly significant due to the natural variation in singing behaviours of different individuals. We tested for significant differences between stages or time of year in each model using a Tukey Kramer honestly significant difference (HSD) test.

To compare male and female responsiveness, we used a matched pairs t-test for within each stage on sub-sampled data so that individuals were only represented once. Following recommendations in Moran (2003), we did not correct for multiple comparisons by adjusting the alpha value or performing Bonferroni adjustments, because we wished to avoid reducing the effect size and power of this study. Figures show nontransformed data, although transformed data were used in statistical analyses. All analyses were conducted in JMP 5.0.3 (SAS, Cary, NC). Means are shown \pm SE; all reported tests are two tailed. 


\section{Results}

Singing Behaviour and Time of Year

Regardless of time of year, rufous-and-white wren pairs sang a greater number of solo songs relative to duets, and paired males sang at higher rates than paired females. However, singing and duetting rates varied substantially with time of year.

At our study site in Parque Nacional Santa Rosa, the average start date for the rainy season in 2004 to 2006 was 14 May, based on the date of when the first sustained rainfall was observed (18 May, 2004; 15 May, 2005; 10 May, 2006); this corresponded with dramatic changes in temperate and relative humidity (Fig 2.1).

Rufous-and-white wren pairs produced more duets early in the year during the dry season, and duet rates decreased with the onset and progression of the rainy season.

Overall, duetting rates were highest in early April (Fig. 2.2a; ANOVA: $F_{23,92}=2.31, P=$ 0.003; model effects: month $\mathrm{F}_{1,7}=3.68, P<0.002$, pair $\mathrm{F}_{1,16}=1.49, P=0.12$ ). During this peak in duet behaviour, duets made up $13.8 \pm 2.7 \%$ of rufous-and-white wren vocalizations, whereas duets made up only $0.9 \pm 0.3 \%$ of vocalizations in early July when duets were least frequent.

Rufous-and-white wren pairs produced the highest number of combined solo songs (i.e. male plus female solos) per hour in late May, coinciding with the onset of the rainy season. Combined solo song rates peaked at this time and remained elevated for the duration of the study. Combined solo song rates during the dry season were significantly lower, with the lowest solo rates occurring in late March (Fig. 2.2b; ANOVA: $F_{23,92}=$ 9.57, $P<0.0001$; model effects: month $\mathrm{F}_{1,7}=24.83, P<0.0001$, pair $\mathrm{F}_{1,16}=1.94, P=$ 
0.03 ). During the peak in solo singing behaviour, duets made up roughly $3.2 \pm 1.0 \%$ of rufous-and-white wren vocalizations.

Females sang a greater number of songs early in the year. Independent song rate for females peaked in early April (Fig. 2.2c; ANOVA: $F_{23,92}=2.86, P<0.0002$; model effects: month $\mathrm{F}_{1,7}=5.00, P<0.0001$, female $\left.\mathrm{F}_{1,16}=2.19, P=0.01\right)$. On average $45.0 \pm$ $8.6 \%$ of all songs recorded per hour were sung by females in March (mid dry season) and $19.0 \pm 2.8 \%$ in early May (late dry season), versus $6.2 \pm 1.8 \%$ in late May (early rainy season) and $2.3 \pm 0.9 \%$ in early July(mid rainy season). Male independent song rates peaked in late May and remained elevated into early July (Fig. 2.2d; ANOVA: F23, $92=9.47, P<0.0001 ;$ model effects: month $\mathrm{F}_{1,7}=24.47, P<0.0001$, male $\mathrm{F}_{1,16}=2.16, P$ $=0.01)$. During this peak in independent song, males sang on average $93.1 \pm 2.2 \%$ of all songs recorded per hour.

\section{Singing Behaviour and Breeding Stage}

Regardless of breeding stage, rufous-and-white wren pairs sang a greater number of solo songs than duets, and paired males sang at higher rates than paired females. However, singing and duetting rates varied substantially with breeding stage.

Duet rates for pairs were highest early in the breeding season. Overall, duet rates were high in the pre-breeding stage and were lowest in the incubation and nestling stages (Fig. 2.3a; ANOVA: $F_{21,93}=2.62, P<0.001 ;$ model effects: breeding stage $F_{1,5}=5.50, P$ $<0.0002$, pair $\left.\mathrm{F}_{1,16}=1.69, P=0.06\right)$. At their highest level, duets made up $15.6 \pm 2.5 \%$ of rufous-and-white wren vocalizations, whereas duet songs made up only $1.0 \pm 0.6 \%$ of the total songs sung during the nestling stage. 
Rufous-and-white wren pairs produced a higher number of combined solo songs per hour in later breeding stages. Overall, combined solo rates peaked during the female's fertile period and were lowest during the pre-breeding stage (Fig 2.3b; ANOVA: $F_{21,93}=$ $5.19, P<0.0001$; model effects: breeding stage $\mathrm{F}_{1,5}=15.78, P<0.0001$, pair $\mathrm{F}_{1,16}=1.39$, $P=0.16$ ). During the peak in combined solo singing behaviour, duets made up $3.5 \pm 1.1$ $\%$ of rufous-and-white wren vocalizations.

Female independent song rates were high in the pre-breeding stage and were lowest during the incubation and nestling stages (Fig. $2.3 \mathrm{c}$; ANOVA: $\mathrm{F}_{21,93}=3.37, P<$ 0.0001 ; model effects: breeding stage $F_{1,5}=7.72, P<0.0001$, female $F_{1,16}=1.92, P=$ 0.03). Male independent song rates peaked later than female rates and were highest during the fertile period (Fig. $2: 3 \mathrm{~d}$; ANOVA: $F_{21,93}=5.23, P<0.0001$; model effects: breeding stage $\mathrm{F}_{1,5}=15.86, P<0.0001$, male $\left.\mathrm{F}_{1,16}=1.44, P=0.14\right)$.

\section{Duetting Behaviour and Breeding Stage}

The proportion of songs sung by males and females did not vary significantly throughout the breeding season; males always sang proportionately more songs than females (Fig. 2.4a; Sign test: $P<0.03$ ). Female rufous-and-white wrens contributed the most to songs (solos and duets combined) during the pre-breeding period (Fig. 2.4a; ANOVA: $\mathrm{F}_{21,93}=8.11, P<0.0001$; model effects: breeding stage $\mathrm{F}_{1,5}=22.55, \mathrm{P}<$ 0.0001 , female $\mathrm{F}_{1,16}=2.96, P<0.001$ ). Male rufous-and-white wrens vocalization behaviour peaked first when females were fertile, and continued at a high level during the incubation and nestling stages (Fig. 2.4a; ANOVA: $F_{21,93}=8.07, P<0.0001$; model effects: breeding stage $\mathrm{F}_{1,5}=21.91, P<0.0001$, male $\mathrm{F}_{1,16}=3.11, P<0.001$ ). 
Regardless of breeding stage, the majority of duets were created by females responding to their partner's songs (Fig. $2.4 \mathrm{~b}$; Sign test: $P<0.03$ ). Females created a similar proportion of duets across all breeding stages (Fig. 4b; ANOVA: $\mathrm{F}_{21,76}=0.90, P$ $<0.59$; model effects: breeding stage $\mathrm{F}_{1,5}=0.78, P=0.57$, female $\mathrm{F}_{1,16}=0.89, P=0.58$ ). Males created a similar, but lower proportion of duets across all breeding stages (Fig. $2.4 \mathrm{~b}$; ANOVA: $\mathrm{F}_{21,76}=0.90, P=0.60$; model effects: breeding stage $\mathrm{F}_{1,5}=0.78, P=$ 0.57 , male $\mathrm{F}_{1,16}=0.89, P=0.58$ ).

Despite the above patterns, the responsiveness of rufous-and-white wrens to their partner's song changed for both males and females over the course of the breeding season. Overall, as the breeding season progressed females became less responsive to their partner's song, and males became more responsive to females. Female rufous-andwhite wrens were most responsive to their partner's song in the pre-breeding stage and least responsive when incubating (Fig. 2.5a; ANOVA: $F_{21,93}=4.67, P<0.0001$; model effects: breeding stage $F_{1,5}=13.73, P<0.0001$, female $F_{1,16}=1.46, P=0.13$ ). For males, their tendency to answer their partner's song peaked during the females fertile period and was significantly higher than their tendency to respond to their partner during the prebreeding period when males were least responsive (Fig. 2.5b; ANOVA: $\mathrm{F}_{21,73}=3.25, P<$ 0.0001 ; model effects: breeding stage $\mathrm{F}_{1,5}=3.88, P<0.01$, male $\mathrm{F}_{1,16}=3.05, P<0.001$ ).

When comparing responsiveness between males and females within each stage we found that males and females do not always respond to their partner's song to the same degree (Fig. 2.5). Males and females were similarly responsive to their partner's song during the pre-breeding (paired test: $\mathrm{t}_{10}=0.83, P=0.42$ ), nestling (paired t test: $\mathrm{t}_{3}=$ $1.17, P=0.33$ ) and post-predation stages (paired t test: $\mathrm{t}_{2}=3.56, P=0.07$ ), although non- 
significant results during the nestling and post-predation stages could be a result of small sample sizes. Males responded significantly more than females to their partner's song during the nest-building (paired $\mathrm{t}$ test: $\mathrm{t}_{16}=2.37, P=0.03$ ), fertile (paired $\mathrm{t}$ test: $\mathrm{t}_{8}=4.98$, $P=0.001$ ) and incubation periods (paired $\mathrm{t}_{10}=5.98, P=0.0001$ ).

\section{Discussion}

Duetting and individual singing rates of male and female rufous-and-white wrens changed significantly with time of year and breeding stage. This suggests that songs sung as duets or as solos have different roles at different stages and at different times of the year. Females are responsible for driving the seasonal and breeding stage patterns of duetting; females create the majority of duets regardless of season or nesting stage. Male song instead appears to drive solo singing patterns; males produce the majority of independent songs regardless of time or year or breeding stage. Male and solo song peaks with the onset of the rainy season, followed shortly by the majority of females laying their first clutches. Overall, duet rates were highest early in the year during the prebreeding stage and solo songs were highest during the female's fertile period. The proportion of their partner's songs that individuals answer to form duets varied between the sexes and with context, suggesting that duetting may result from both conflict and cooperation between the sexes.

Duetting and solo song: A function of joint and independent territory defence?

In rufous-and-white wrens, our evidence suggests that one function of high duet rates early in the year is for territory defence. Male and female rufous-and-white wrens have been found previously to respond aggressively to simulated duet playback 
conducted during the nest building stage, by singing duets and solos songs at much higher rates than normal (Mennill 2006). In addition, Mennill (2006) tested male and female responsiveness during playback trials and found that males and females were equally responsive to their partner's song during simulated territorial intrusions. Equal levels in responsiveness to a partner's song between males and females have been suggested as a sign of cooperation between the sexes (Hall 2004). In the present study, we found that partner responsiveness varied dramatically between the sexes during each breeding stage, indicating a possible change in song function with breeding stage. However, during the pre-breeding season males and females showed an equal level of responsiveness to each other's songs. This supports previous findings (Mennill 2006) and suggests that duetting in the pre-breeding season is a function of rufous-and-white wren pairs cooperatively defending resources from conspecific rivals.

Seasonal changes in female song have been documented for a number of temperate (e.g. northern cardinals, Ritchison 1986; Vondrasek 2006; song sparrows, Arcese et al. 1988; white-crowned sparrows, Baptista et al. 1993) and tropical species (e.g. magpie lark, Grallina cyanoleuca, Tingay 1974; Hall 2006; bar-throated apalis, Apalis flavida, Harcus 1977; superb fairy wrens, Cooney \& Cockburn 1995; redshouldered blackbird, Agelaius assimilis, Whittingham et al. 1997; bellbird, Anthornis melanura, Brunton \& Li 2006). In most cases female song, whether sung as part of duet or as a solo, peaks prior to the start of the breeding season before nest building has begun (e.g. Vondrasek 2006; Hall 2006). In this study, we also found that female independent song rates were highest early in year, prior to breeding. For example, in March females sang $45.0 \pm 8.6 \%$ of all songs, whereas in late May females only sang $6.2 \pm 1.8 \%$ of all 
songs sung within a partnership. During the pre-breeding period females sang $28.9 \pm 3.6$ $\%$ of all songs, whereas they only sang $1.9 \pm 0.8 \%$ of all songs during the nestling breeding stage.

In non-duetting species a peak in female song prior to nesting appears to result from an increase in female aggression during the defence of a territory or resource (Langmore 1998). For example, female white-crowned sparrows only responded aggressively to playback and sang in territorial conflicts with both sexes prior to nest building (Baptista et al. 1993). In female superb fairy-wrens (Cooney \& Cockburn 1995) and female northern cardinals (Vondrasek 2006), song rates were found to be highest when birds were reasserting or defending territorial boundaries against intruders prior to nesting. Again, once the breeding season commenced aggressive encounters and song in these species decreased significantly (Cooney \& Cockburn 1995; Vondrasek 2006), suggesting that the primary function of female song is for resource defence. In tropical species, few studies have addressed how pair duets and female song change seasonally, therefore the meaning of a peak in duetting and female independent song prior to breeding is still largely speculative. However, the use of playback to assess duet function has provided evidence that duets and female song are also used to defend territories or resources in tropical species generally (Hall 2004) and rufous-and-white wrens in particular (Mennill 2006). In most cases, both males and females respond aggressively to the playback of simulated intrusions by increasing solo song and duet song rates (e.g. bay wren, Thryothorus nigricapillus, Levin 1996b; magpie-larks, Hall 2000; eastern whipbird, Rogers et al. 2006). 
Only two studies to date have assessed seasonal changes in song using playback in the tropics (Hall 2000; Fedy \& Stutchbury 2005) In both cases, duets and solo songs are used in territorial displays, however in magpie-larks no seasonal variation was found in the response of males and females to intruders (Hall 2000). This suggests that some resources may be limited year-round, requiring equally aggressive responses to duetting regardless of the season (Hall 2000). In the case of the white-bellied antbirds, pairs responded more aggressively during the dry (pre-breeding) season than the wet season, suggesting that resource competition varies seasonally (Fedy \& Stutchbury 2005), as is the case for temperate females that sing (Arcese et al. 1988; Baptista et al. 1993).

The combination of year-round territoriality, low adult mortality, long-post fledgling care, and delayed dispersal in tropical species (Skutch 1985; Martin 1996; Slater \& Mann 2004) may create periods where the pressure for resources or territories is unusually high. In high pressure periods, duetting may peak as joint territory or resource defence may be a more effective display than solo songs at excluding intruders (Hall 2004). We observed the highest number of non-territorial birds (floaters) in March and early April, suggesting that competition for breeding territories is highest at this time of year. As such, the observed peak in duetting at this time of year lends support to the idea that duets are important in territory defence (Seibt \& Wickler 1977; Hall 2004). However, Levin (1996a) found that duetting is not necessary for territory defence in bay wrens, as unpaired individuals were able to maintain territories. The importance of duets in territory defence requires further investigation.

With the initiation of the breeding season, male rufous-and-white wren independent song increases, while duetting decreases, which may imply that once 
territory re-establishment has occurred and neighbourhoods have become relatively stable males take over the role of teritory defence. As male independent song rate peaks and remains high following the female's fertile period, it is likely that solo song is now used to defend territories as a 'keep-out' signal to rival males (Kacelnik \& Krebs 1983; Kunc et al. 2005). In some temperate species, unmated or non-territorial males prospect for new territories or mates at dawn (Amrhein et al. 2004). Therefore, there may be pressure for territorial males to announce their status at dawn throughout the breeding season (Kunc et al. 2005).

Studies of temperate birds also reveal high male independent song rates throughout the breeding season. In temperate regions, a peak in dawn song during the female's fertile period or at the onset of incubation has been observed in many species (reviewed in Kunc et al. 2005). In species in which a peak in song is not limited to the female's fertile period, it is suggested that continued dawn singing is used to maintain territories (e.g. Stacier et al. 1996; Liu 2004; Kunc et al. 2005). For example, Liu (2004) examined the interactions of neighbours and females on dawn and daytime singing in male chipping sparrows, Spizella passerina, and found that dawn song functions in territory defence and is sung throughout the breeding season, while daytime singing is used to attract females (Liu 2004). Removal of all neighbours surrounding a male's territory significantly reduced or even stopped the dawn singing from the solitary male (Lui 2004). In our study population in 2006, one rufous-and-white wren pair had no surrounding neighbours, and we observed reduced male independent song rates throughout the breeding season, lending support that continued male song is important for intersexual interactions and territory defence. 
Duetting and solo song: A function of reproductive synchrony?

High duet rates early in the year and high male independent song during the breeding season could also result from song being used cooperatively to coordinate breeding activities (Dilger 1953). Few studies have tested this hypothesis; however, a peak in duet behaviour prior to nest-building and again after predation events is suggestive of duets synchronizing breeding activities within a pair (Dilger 1953; Hall 2004). In this study, we found that pairs were equally responsive to each other's song following predation events and during the pre-breeding and nestling stages, but not during nest-building, the female's fertile period or incubation stages. Following predation events we also found a tendency for duet rates to peak again, although this trend was not statistically supported. Increases in duet behaviour following predation events have been documented in the slate-coloured boubous, Laniarus funebris, (Sonnenschein \& Reyer 1983) and a resurgence in male song has been documented in mockingbirds, Mimus polyglottos, (Logan 1983) adding support to this hypothesis. In addition, rufous-andwhite wren pairs were observed duetting close together and in association with choosing alternate nest sites following predation events (pers. obs.). However, our results could be an artifact of few recordings of pairs following nest predation event $(\mathrm{N}=3)$ and large variation in singing behaviour between pairs during both of these stages.

Additionally, a peak in male independent song with the onset of the rainy season and the female fertile period may also be the stimulus needed to fine tune reproductive activities to coincide with the time of year when resources are most plentiful. Tropical species are able to detect slight changes in photoperiod and use this cue to initiate breeding activities (e.g. nest building) (Hau et al 1998; Wikelski et al. 2000; Hau 2001), 
however there are fewer environmental cues of seasonality (Hau et al. 2000) and the onset of the rainy season is highly variable from year to year (Ahumada 2001). Both temperate and tropical species time reproduction for when conditions are optimal (i.e. high food availability) (Slater \& Mann 2004). As the timing of optimal conditions is less predictable in the tropics, tropical species may remain in a state of 'readiness to breed' for large portions of the year (Hau 2000; Dawson et al. 2001). Song has been shown in temperate species to be important for stimulating females to reproduce (e.g. Kroodsma 1976); because male song rate peaks at the onset of the rainy season and there is a trend for duetting to increase following predation events, it may be that duets and an increase in male independent song are important for synchronizing reproductive activities. In this case, duets may be important for coordinating joint activities, such as nest building, while high rates of male independent song may provide a mechanism for rapidly adjusting the reproductive state of females (Logan 1983). This has been suggested as an explanation for the cyclical pattern of song use that occurs in mockingbirds during the breeding season (Logan 1983). Further investigation into both the territory defence and reproductive synchrony hypothesis is warranted, although it is likely that duets for rufous-and-white wrens are used cooperatively in both contexts.

\section{Changes in male responsiveness: A function of mate and/or paternity guarding?}

In our study, seasonal variation and breeding stage patterns in male song provide additional evidence that duets and solo songs functions in same-sex communication for male rufous-and-white wrens. Evidence for this is: (1) male responsiveness to his partner's song peaks when females are fertile, yet at the same time female song rate is 
decreasing; and (2) male independent song rate shows a dramatic increase when females become fertile. The peak in male responsiveness during the fertile stage suggests that duets may act as a mate or paternity guard when females are fertile (Sonnenschein \& Reyer 1983; Hall 2004). That is, males may create duets with their partner's songs to advertise their partner's mated status. Variation in male song with time of year and breeding stage has been well documented for temperate songbirds (e.g. Slagsvold 1977, Logan 1983). In numerous temperate species, male dawn song rate peaks during the female's fertile period (e.g. European blackbird, Turdus merula, Cutthill \& MacDonald 1990; European starlings, Sturnus vulgaris, Pinxten \& Eens 1998). A peak in song rate during this breeding stage has been interpreted by some as evidence that male song plays a role in mate-guarding (Cutthill \& MacDonald 1990) and/or paternity guarding (GregSmith 1982; Møller 1991).

For duetting species, mate and paternity guarding have recently been proposed as hypotheses representing conflict between the sexes and alternative functions for duets (reviewed in Hall 2004). In assessing these hypotheses, it is important to assess the likelihood of an individual joining its partner's song to create a duet. For mate-guarding to occur, individual males or females are expected to respond to more of their partner's songs when their position in a partnership is threatened (Levin 1996b; Hall 2004). For acoustic paternity guarding, males are expected to respond to more of their partner's song when she is fertile to discourage extra pair copulations (Levin 1996b; Hall 2004). Evidence from stereo duet playback on rufous-and-white wrens suggests that duets function in communication with same-sexed intruders for males, acting as a mate and/or paternity guard, in addition to joint territory defence (Mennill 2006). Male rufous-and- 
white wrens were found to respond with a higher level of aggression to speakers playing male song than female song, suggesting that same-sex intruders are perceived as more of a threat than intruding females (Mennill 2006). Female response did not vary with the sex of the intruder (Mennill 2006). The genetic mating system of rufous-and-white wrens is still unknown; however females have been observed making forays into neighbouring male territories prior to laying (pers. obs). Males also follow females closely when they are fertile (pers. obs.), therefore it may be necessary for males to guard their paternity.

Evidence from studies examining duet function as an acoustic mate-guard or paternity guard are equivocal (Hall \& Magrath 2000; Seddon et al. 2002; Stutchbury et al. 2005; Rogers et al. 2006), therefore further research using playback to assess singing strategies and responsiveness of males and females during different breeding stages would be beneficial for understanding the degree to which males use duet song in samesex communication.

\section{Conclusion}

Our results highlight the need for a greater understanding of how individuals and mated pairs contribute to the variation in solo and duet song during different seasons and breeding stages in duetting species. This study clearly shows that duets act as multifunctional signals for rufous-and-white wrens, with duet function changing with time of year or breeding stage. On the one hand, duets may act as a cooperative pair signal, facilitating territory defence and breeding synchrony early in the breeding season.

On the other hand, duetting behaviour may represent conflict between the sexes with male duet responsiveness discouraging opportunities for rival males to usurp his 
partnership or paternity. Further research into the complex behaviour of duetting will surely yield genera! insights into sexual conflict and cooperation in animals. 


\section{References}

Ahumada, J. A. 2001. Comparison of the reproductive biology of two neotropical wrens in an unpredictable environment in northeastern Colombia. Auk, 118, 191-120.

Amrhein, V., Kunc, H. P. \& Naguib, M. 2004. Non-territorial nightingales prospect territories during the dawn chorus. Proceedings of the Royal Society of London, Series B (Suppl.), 271, S167-S169.

Arcese, P., Stoddard, P. K. \& Hiebert, S. M. 1988. The form and function of song in female song sparrows. Condor, 90, 44-50.

Ballentine, B., Badyaev, A. \& Hill, G. E. 2003. Changes in song complexity correspond to periods of female fertility in blue grosbeaks (Guiraca caerulea). Ethology, 109, $55-66$.

Baptista, L. F., Trail, P. W., Dewolfe, B. B. \& Morton, M. L. 1993. Singing and its functions in female white-crowned sparrows. Animal Behaviour, 46, 511-524.

Brunton, D. H. \& Li, X. 2006. The song structure and seasonal patterns of vocal behavior of male and female bellbirds (Anthornis melanura). Journal of Ethology, 34, 17-25.

Catchpole, C. K. 1973. The function of advertising song in the sedge warbler (Acrocephalus schoenobaenus) and the reed warbler (A. scirpaceus). Behaviour, 46, 300-320.

Cooney, R. \& Cockburn, A. 1995. Territorial defence is the major function of female song in the superb fairy-wren, Malurus cyaneus. Animal Behaviour, 49, 16351647.

Cuthill, I. C. \& Macdonald, W. A. Experimental manipulation of the dawn and dusk chorus in the blackbird Turdus merula. Behavioural Ecology and Sociobiology, 26, 209-216.

Dawson, A., King, V. M., Bentley, G. E. \& Ball, G. F. 2001. Photoperiodic control of seasonality in birds. Journal of Biological Rhythms, 16, 365-380.

Dilger, W. C. 1953. Duetting in the crimson-breasted barbet. Condor, 55, 220-221.

Farabaugh, S. M. 1982. The ecological and social significance of duetting. In: Acoustic Communication in Birds. Vol. 2 (Ed. by D. E. Kroodsma \& E. H. Miller), pp. 85124. New York: Academic Press.

Fedy, B. C. \& Stutchbury, J. M. 2005. Territory defence in tropical birds: are females as aggressive as males? Behavioral Ecology and Sociobiology, 58, 414-422. 
Gill, S. A., Vonhof, M. J., Stutchbury, B. J. M., Morton, E. S. \& Quinn, J. S. 2005. No evidence for acoustic mate-guarding in duetting buff-breasted wrens (Thryothorus leucotis). Behavioural Ecology and Sociobiology, 57, 557-565.

Grafe, T. U. \& Bitz, J. H. 2004. The functions of duetting in the tropical boubou (Laniarius aethiopicus): territorial defence and mutual mate-guarding. Animal Behaviour, 68, 193-201.

Greg-Smith, P. W. 1982. Seasonal patterns of song production by male stonechats Saxicola torquata. Ornis Scandinavica, 13, 225-231.

Hall, M. L. 2000. The function of duetting in magpie-larks: conflict, cooperation, or commitment? Animal Behaviour, 60, 667-677.

Hall, M. L. 2004. A review of hypotheses for the functions of avian duetting. Behavioral Ecology and Sociobiology, 55, 415-430.

Hall, M. L. 2006. Convergent vocal strategies of males and females are consistent with a cooperative function of duetting in Australian magpie-larks. Behaviour, 143, 425449.

Hall, M. L. \& Magrath, R. D. 2000. Duetting and mate-guarding in Australian magpielarks (Grallina cyanoleuca). Behavioural Ecology and Sociobiology, 47, 180-187.

Harcus, J. L. 1977. The functions of vocal duetting in some African birds. Zeitschrift Fur Tierpsychologie, 43, 23-45.

Hau, M. 2001. Timing of breeding in variable environments: tropical birds as model systems. Hormones and Behavior, 40, 281-290.

Hau, M., Wikelski, M. \& Wingfield, J. C. 1998. A neotropical bird can measure the slight changes in tropical photoperiod. Proceedings of the Royal Society of London Series B, 265, 89-95.

Hau, M., Wikelski, M. \& Wingfield, J. C. 2000. Visual and nutritional food cues finetune timing of reproduction in a neotropical rainforest bird. Journal of Experimental Zoology, 286, 494-504.

Kacelink, A. \& Krebs, J. R. 1983. The dawn chorus in the great tit (Parus major): proximate and ultimate causes. Behaviour, 83, 287-309.

Kroodsma, D. E. 1976. Reproductive development in a female songbird: differential stimulation by quality of male song. Science, 192, 574-575.

Kunc, H. P., Amrhein, V., \& Naguib, M. 2005. Seasonal variation in dawn song characteristics in the common nightingale. Animal Behaviour, 70, 1265-1271. 
Lampe, H. M. \& Espmark, Y. O. 1987. Singing activity and song pattern of the Redwing Turdus iliacus during the breeding season. Ornis Scandinavica, 18, 179 185.

Langmore, N. E. 1998. Functions of duet and solo songs of female birds. Trends in Ecology \& Evolution, 7, 136-140.

Levin, R. N. 1996a. Song behaviour and reproductive strategies in a duetting wren, Thryothorus nigricapillus: I. Removal experiments. Animal Behaviour, 52, 1093 1106.

Levin, R. N. 1996b. Song behaviour and reproductive strategies in a duetting wren, Thryothorus nigricapillus: II. Playback experiments. Animal Behaviour, 52, 11071117.

Liu, W.-C. 2004. The effect of neighbours and females on dawn and daytime singing behaviours in male chipping sparrows. Animal Behaviour, 68, 39-44.

Logan, C. A. 1983. Reproductively dependent song cyclicity in mated male mockingbirds (Mimus polyglottos). Auk, 100, 404-413.

Logue, D. M. \& Gammon, D. E. 2004. Duet song and sex roles during territory defence in a tropical bird, the black-bellied wren, Thryothorus fasciatoventris. Animal Behaviour, 68, 721-731.

Moran, M. D. 2003. Arguments for rejecting the sequential Bonferroni in ecological studies. Okios, 100, 403-405.

Martin, T. E. 1996. Life-history evolution in tropical and south temperate birds: what do we really know? Journal of Avian Biology, 27, 263-272.

Mennill, D. J. 2006. Aggressive responses of male and female rufous-and-white wrens to stereo duet playback. Animal Behaviour, 71, 219-226.

Mennill, D. J., \& Verehncamp, S. L. 2005. Sex differences in the singing and duetting behaviour of neotropical rufous-and-white wrens (Thryothorus rufalbus). Auk, 122, 175-186.

Moller, A. P. Why mated songbirds sing so much: mate guarding and male announcement of mate fertility status. American Naturalist, 138, 994-1014.

Otter, K., Chruszez, B. \& Ratcliffe, L. 1997. Honest advertisement and song output during the dawn chorus of black-capped chickadess. Behavioural Ecology \& Sociobiology, 8, 167-173.

Pinxten, R. \& Eens, M. 1998. Male starlings sing most in the late morning, following egg-laying: a strategy to protect their paternity? Behaviour, 135, 1197-1211. 
Ritchison, G. 1986. The singing behavior of female northern cardinals. Condor, 88, 156159.

Rogers, A. C., Mulder, R. A. \& Langmore, N. E. 2006. Duet duels: sex differences in song matching in duetting eastern whipbirds. Animal Behaviour, 72, 53-61.

Rogers, A. C., Langmore, N. E. \& Mulder, R. A. 2007. Function of pair duets in the eastern whipbird: cooperative defence or sexual conflict? Behavioral Ecology, 18, 182-188.

Seddon, N., Butchart, S. H. M. \& Odling-Smee, L. 2002. Duetting in the subdesert mesite Monias benschi: evidence for acoustic mate defence? Behavioral Ecology and Sociobiology, 52, 7-16.

Seibt, U. \& Wickler, W. 1977. Duettieren als Revier-Anzeige bei Vogeln. Zeitschrift für Tierpsychologie, 43, 180-187.

Skutch, A. F. 1985. Clutch size, nesting success, and predation on nests of Neotropical birds, reviewed. Ornithological Monographs, 36, 575-594.

Slagsvold, T. 1977. Bird song activity in relation to breeding cycle, spring weather, and environmental phenology. Ornis Scandinavica, 8, 197-222.

Slater, P. J. B. \& Mann, N. I. 2004. Why do females of many bird species sing in the tropics? Journal of Avian Biology, 35, 289-294.

Sonnenschein, E. \& Reyer, H. U. 1983. Mate-guarding and other functions of antiphonal duets in the slate-coloured boubou (Laniarus funebris). Zeitschrift für Tierpsychologie, 63, 112-140.

Stacier, C. A., Spector, D. A. \& Horn, A. G. 1996. The dawn chorus and other diel patterns in acoustic signaling. In: Ecology and Evolution of Acoustic Communication in Birds (Ed. by D. E. Kroodsma \& E. H. Miller), pp. 426-453. London: Cornell University Press.

Stiles, F. G. \& Skutch A. F. 1989. A guide to the birds of Costa Rica. Cornell University Press, Ithaca, N.Y.

Stokes, A. W. \& Williams, H. W. 1968. Antiphonal calling in quail. Auk, 85, 83-89.

Tingay, S. 1974. Antiphonal song of the magpie lark. Emu, 74, 11-17.

Vondrasek, J. R. 2006. Social factors affect the singing rates of female northern cardinals Cardinalis cardinalis. Journal of Avian Biology, 37, 52-57.

Whittingham, L. A., Kirkconnell, A. \& Ratcliffe, L. M. 1997. The context and function of duet and solo songs in the red-shouldered blackbird. Wilson Bulletin, 109, 279-289. 
Wikelski, M., Hau, M. \& Wingfield, J. C. 2000. Seasonality of reproduction in a neotropical rainforest bird. Ecology, 81, 2458-2472. 


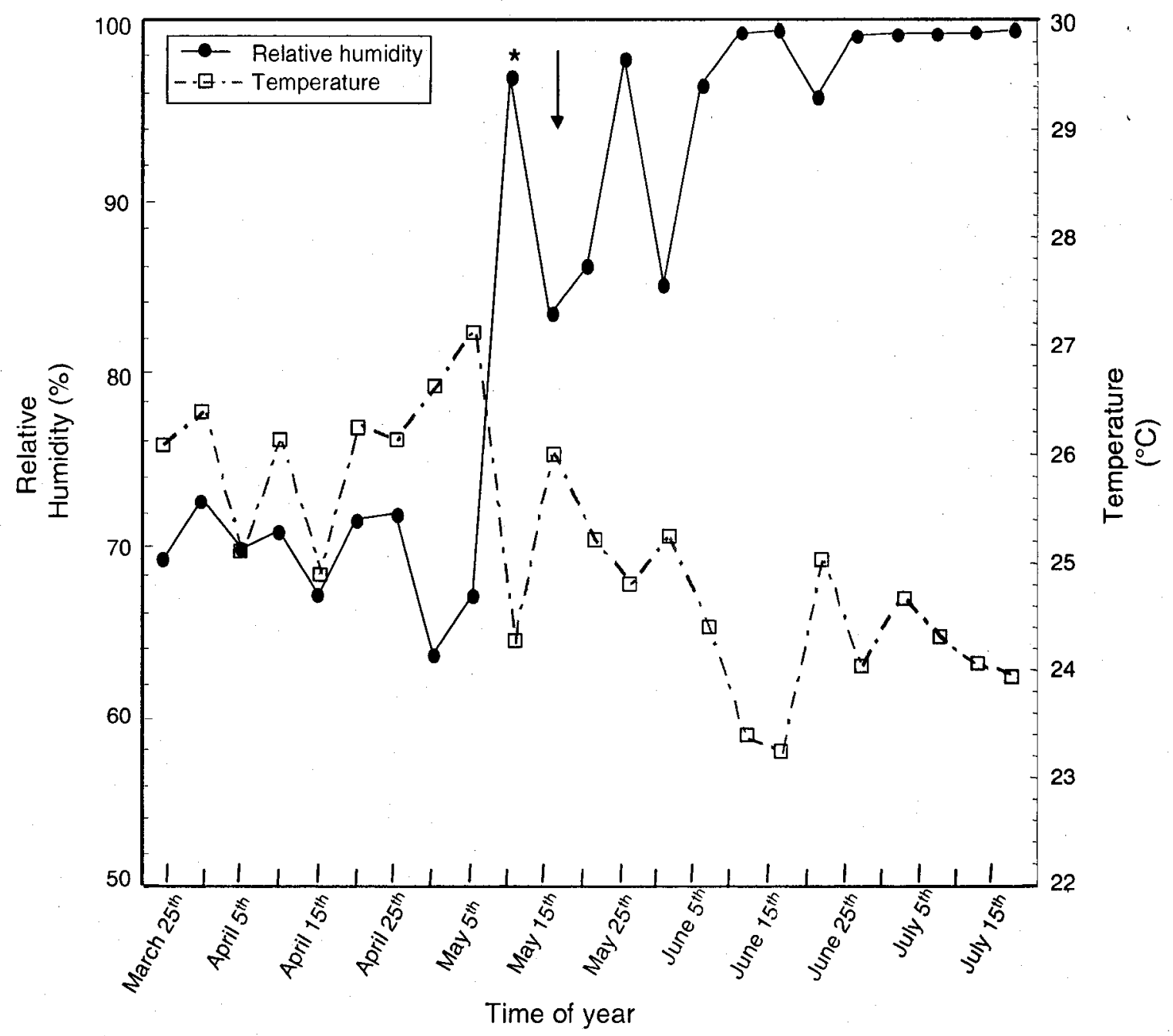

Figure 2.1. Seasonal changes in average daily temperate and relative humidity between mid-March and mid-July at Parque Nacional Santa Rosa. Asterisk indicates the day prolonged rain was first documented, indicating the start of the rainy season. The arrow indicates the average first laying date for first clutches (17 May 2006) $(\mathrm{N}=12$, range 27 Apr-25 May). 

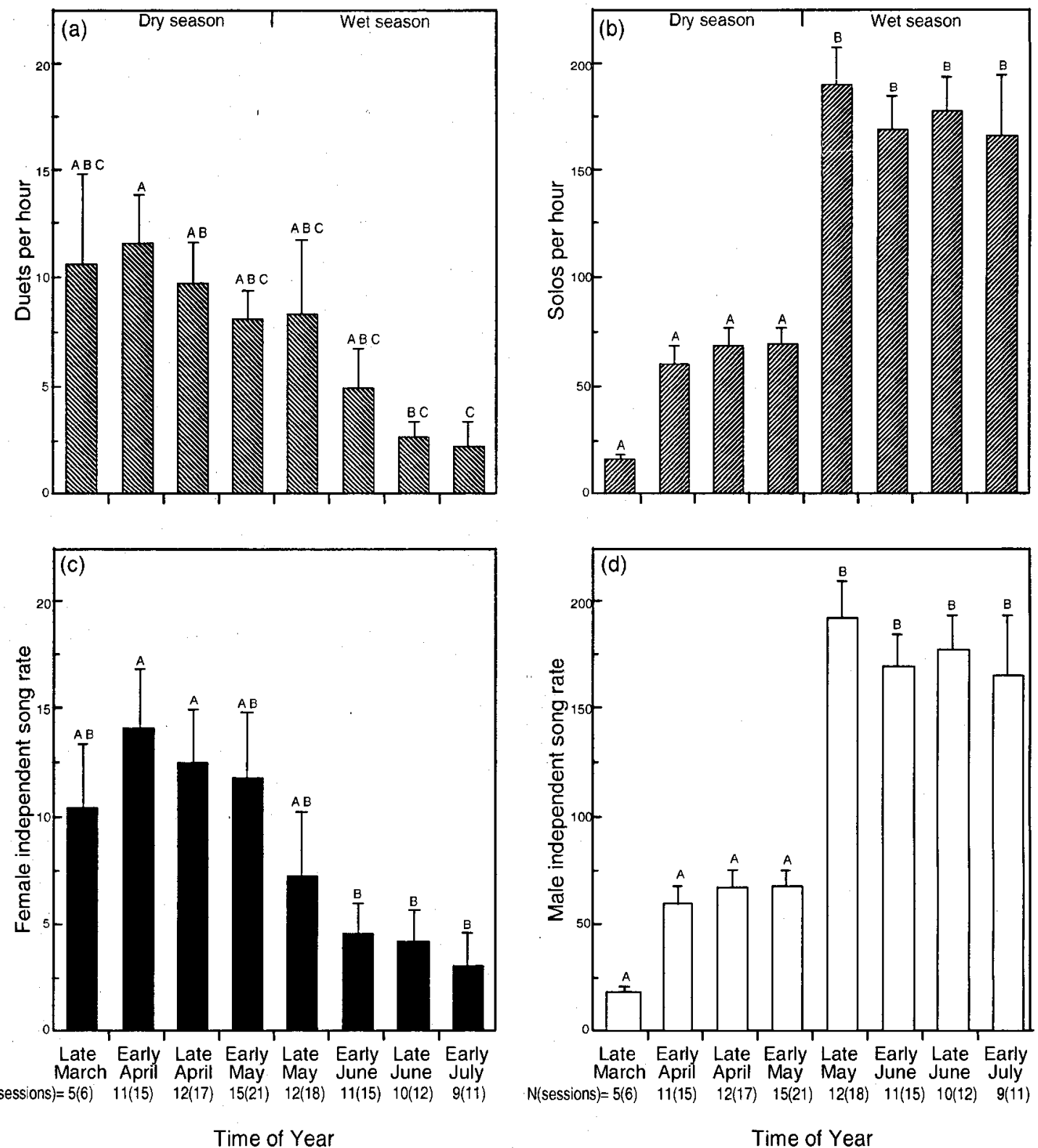

Figure 2.2. Variation in song output (per hour) of rufous-and-white wrens with time of year. (a) Duet output for pairs. (b) Combined male and female solo song output for pairs. (c) Female independent song output (female solos plus duets where female sang first). (d) Male independent song output (male solos plus duets where male sang first). Sample sizes show the number of pairs recorded with the total number of recording sessions in parentheses. 

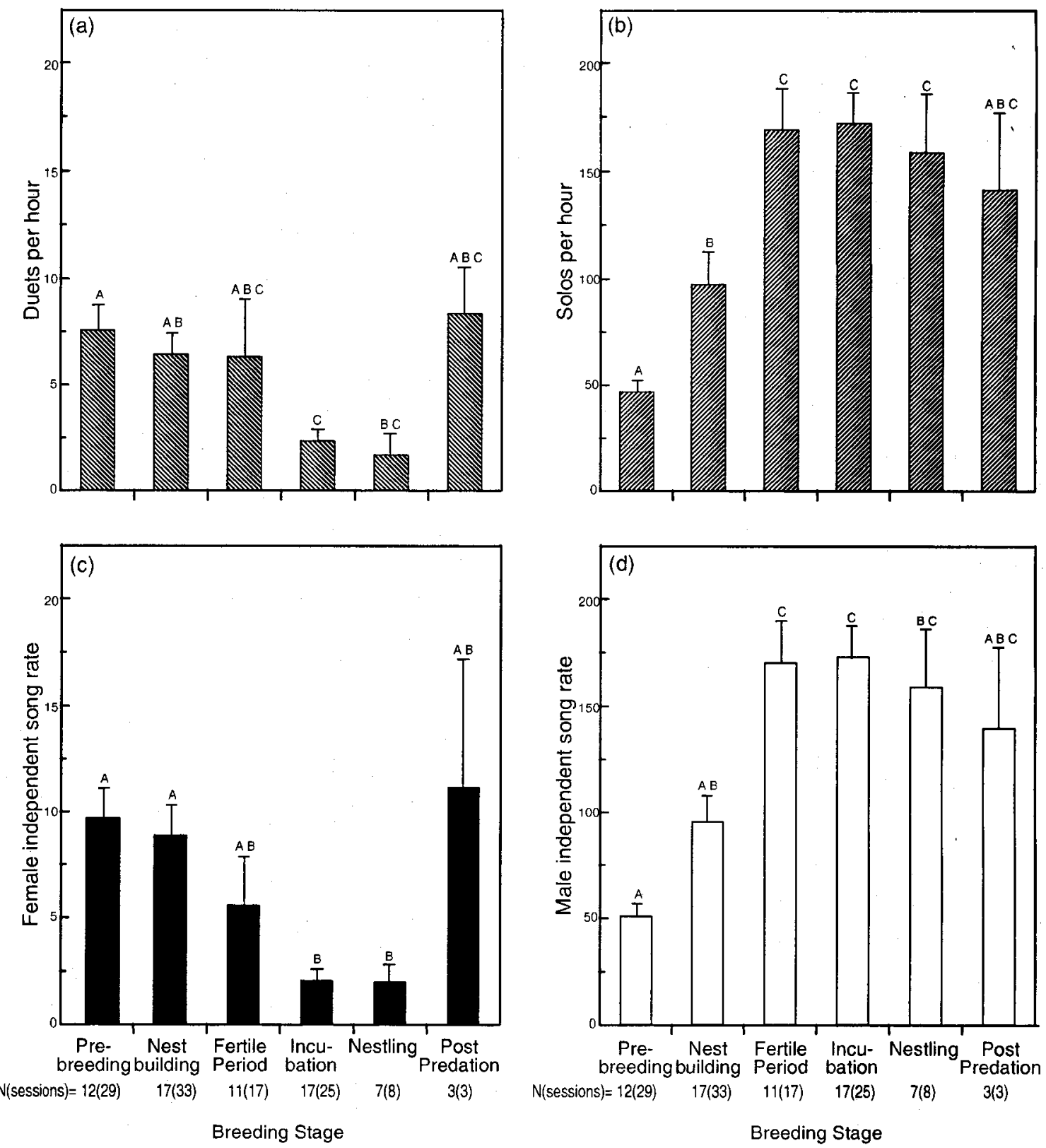

Figure 2.3. Variation in song output (per hour) of rufous-and-white wrens with breeding stage. (a) Duet output for pairs. (b) Combined male and female solo song output for pairs. (c) Female independent song output (female solos plus duets where female sang first). (d) Male independent song output (male solos plus duets where male sang first). Sample sizes show the number of pairs recorded with the total number of recording sessions in parentheses. 

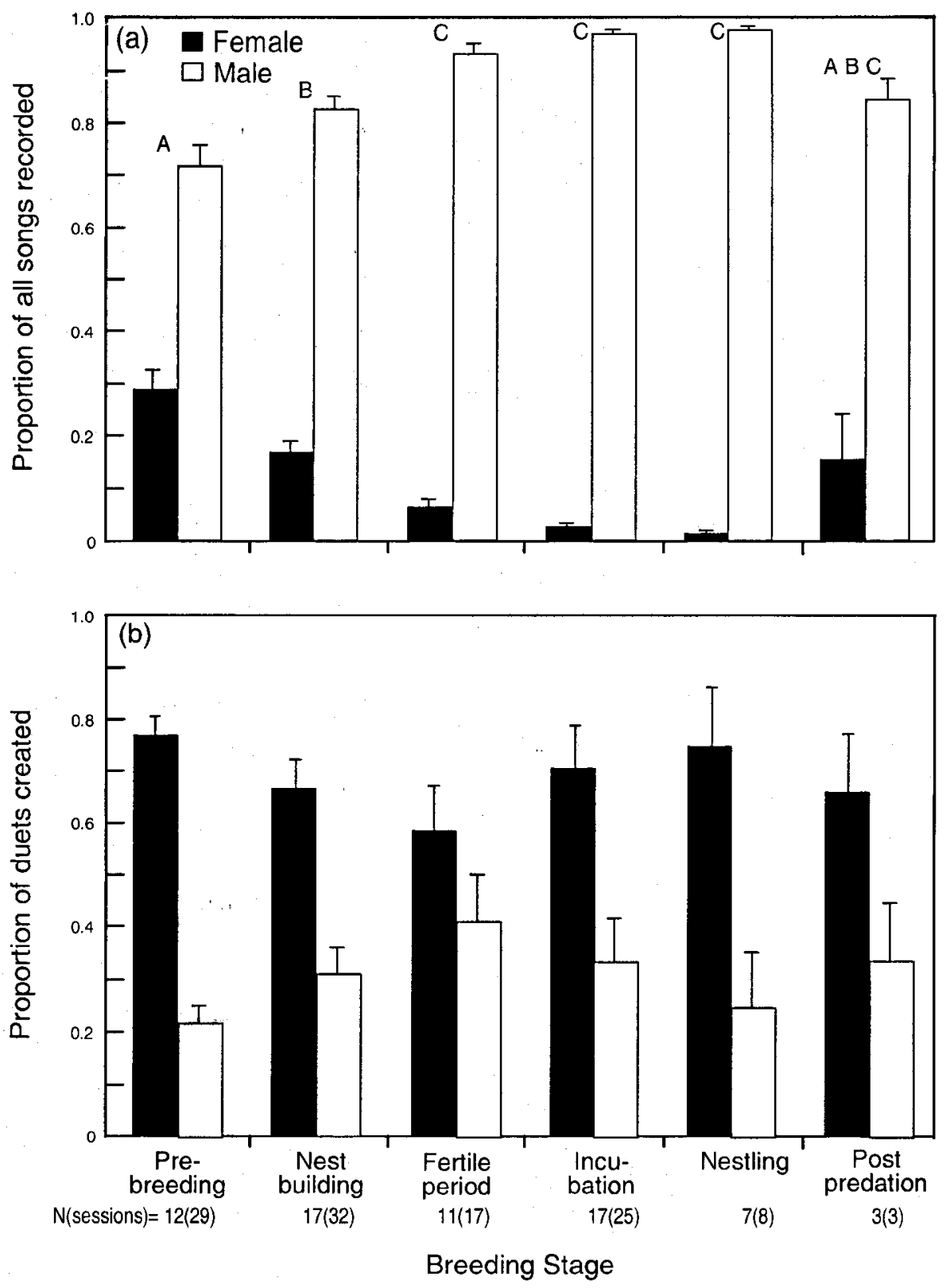

Figure 2.4. Variation in the proportion of song output per hour of female and male rufous-and-white wrens with breeding stage. (a) Proportion of total songs sung by females and males. (b) Proportion of male and female created duets. Sample sizes show the number of pairs recorded with the total number of recording sessions in parentheses. Sample sizes for (b) are reduced: data were missing for 1 pair in the pre-breeding, 2 in the fertile, 6 in the incubation, and 4 the in nestling stages because some females did not duet. 

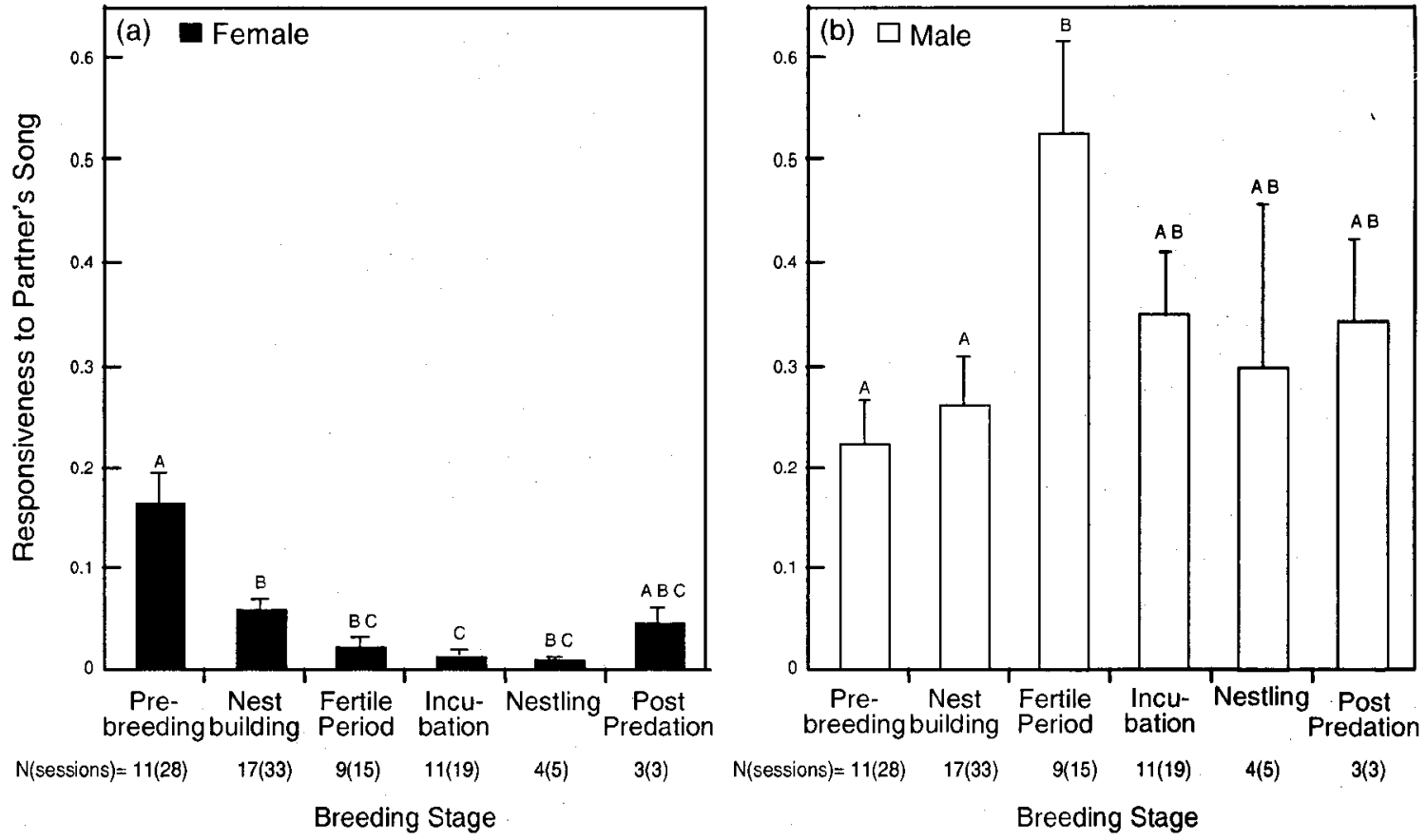

Figure 2.5. Variation in the male and female rufous-and-white wren responsiveness with breeding stage. (a) Responsiveness of females to their partner's song. (b) Responsiveness of males to their partner's song. Sample sizes show the number of pairs recorded with the total number of recording sessions in parentheses. 


\section{Summary and Recommendations}

Our understanding of seasonal patterns of song use in tropical duetting species is rudimentary, and as a result, the relationship between the function of song and season is still poorly understood. We examined how duetting and solo song changed in relation to time of year and breeding stage in a population of rufous-and-white wrens (Thryothorus rufalbus) in Costa Rica. Between March and July of both 2005 and 2006, we recorded a total of 17 mated pairs repeatedly throughout the field season. From these recordings, we analyzed male and female song output (solos and duets), duet frequency (as a proportion of total songs sung in the given time period), assessed proportion of male versus female created duets, and male and female duet responsiveness. We interpret data based on (1) male and female independent singing strategies and (2) duetting strategies.

Overall, we found that duetting is a complex and multifunctional signal for rufous-and-white wrens, whose function varies depending on the season and time of year. In addition, male and females have different seasonal patterns of singing. In general, female song and duet song peaks in the pre-breeding season, early in the year, and it appears that females drive the observed seasonal pattern of duetting. Male song and male responsiveness on the other hand, peak when females are fertile, which coincides with the beginning of the rainy season. These results suggest that duets play a significant role early in the year and may represent cooperative displays, functioning in joint territory defence and in the coordination of breeding activities. However, duet rates decrease when females are fertile but male duet responsiveness peaks, suggesting that duets may also represent conflict between the sexes, functioning as a paternity guard during this breeding stage. 
This study highlights the need for further investigation into the role of duet and solo signing strategies of rufous-and-white wrens with respect to time of year and breeding stage. It is apparent that the function of duets changes depending on context and environmental conditions. Additional experimental research, such as conducting repeat playback experiments during different breeding stages (e.g. pre-breeding and breeding) (e.g. Hall 2000; Fedy \& Stutchbury 2004), or conducting mate removal experiments, similar to Levin's experiment with bay wrens (1996), would be highly informative in this species. In addition, because females in this species appear to be driving the pattern of temporal variation in duetting, it would be enlightening to have a better understanding and grasp on the significance of female song in the tropics. This field would benefit tremendously from researchers concurrently investigating the role and function of female song in non-duetting tropical species (e.g. banded wren, Thryothorus pleurostictus). Finally, because there is limited information known about the general life-history and breeding biology of the majority of tropical species, and rufous-and-white wrens in particular, this field would benefit from detailed studies investigating life-history characteristics, mating systems, and ecology of tropical species. 


\section{References}

Fedy, B. C. \& Stutchbury, J. M. 2005. Territory defence in tropical birds: are females as aggressive as males? Behavioral Ecology and Sociobiology, 58, 414-422.

Hall, M. L. 2000. The function of duetting in magpie-larks: conflict, cooperation, or commitment? Animal Behaviour, 60, 667-677.

Levin, R. N. 1996. Song behaviour and reproductive strategies in a duetting wren, Thryothorus nigricapillus: I. Removal experiments. Animal Behaviour, 52, 1093 1106. 


\section{Appendix - ANOVA Summary Tables}

ANOVA summary table: Time of year $\mathrm{x}$ combined duet rates (duets/hr)

\begin{tabular}{lrrrr}
\hline $\begin{array}{l}\text { Whole model: } \\
\begin{array}{l}\text { Source of } \\
\text { variation }\end{array}\end{array}$ & SS & df & $\mathrm{s}^{2}$ & F \\
\hline Model & 53.99 & 23 & 2.35 & $2.31^{*}$ \\
Error & 93.47 & 92 & 1.02 & \\
Total & 147.46 & 115 & & \\
\hline
\end{tabular}

Model effects:

\begin{tabular}{lrrrr}
$\begin{array}{l}\text { Source of } \\
\text { variation }\end{array}$ & SS & df & $\begin{array}{c}\text { MS } \\
\text { num }\end{array}$ & F \\
\hline Month & 26.15 & 7 & 3.74 & $3.68^{*}$ \\
$\begin{array}{l}\text { Pair \& } \\
\text { random }\end{array}$ & 24.25 & 16 & 1.52 & 1.49 \\
\hline
\end{tabular}

*Significant at $\mathrm{P}<0.05$

ANOVA summary table: Time of year $\mathrm{x}$ combined solo rates (songs/hr)

\begin{tabular}{lrrrrr}
\hline \multicolumn{2}{l}{ Whole model: } & & & & \\
$\begin{array}{l}\text { Source of } \\
\text { variation }\end{array}$ & SS & df & $\mathrm{s}^{2}$ & $\mathrm{~F}$ \\
\hline Model & 1095.98 & 23 & 47.60 & $9.57^{*}$ \\
Error & 458.07 & 92 & 4.97 & \\
& & & & \\
Total & 1554.05 & 115 & & \\
\hline
\end{tabular}

Model effects:

\begin{tabular}{lrrrr}
$\begin{array}{l}\text { Source of } \\
\text { variation }\end{array}$ & SS & df & $\begin{array}{r}\text { MS } \\
\text { num }\end{array}$ & F \\
\hline Month & 865.39 & 7 & 123.63 & $24.83^{*}$ \\
$\begin{array}{l}\text { Pair \& } \\
\text { random }\end{array}$ & 154.31 & 16 & 9.64 & $1.94^{*}$ \\
\hline
\end{tabular}

*Significant at $\mathrm{P}<0.05$ 
ANOVA summary table: Time of year $\mathrm{x}$ female independent song rates (songs/hr)

\begin{tabular}{|c|c|c|c|c|}
\hline \multicolumn{2}{|c|}{ Whole model: } & ' & \\
\hline $\begin{array}{l}\text { Source of } \\
\text { variation }\end{array}$ & SS & df & $s^{2}$ & $F$ \\
\hline Model & 82.57 & 23 & 3.59 & $2.86^{*}$ \\
\hline Error & 115.41 & 92 & 1.25 & \\
\hline Total & 197.98 & 115 & & \\
\hline
\end{tabular}

Model effects:

Source of MS variation $S S$ df num $F$

\begin{tabular}{lllll}
\hline Month & 43.91 & 7 & 6.27 & $5.00 *$
\end{tabular}

Female\& random

$43.91 \quad 16$

$2.752 .19^{*}$

\footnotetext{
*Significant at $\mathrm{P}<0.05$
}

ANOVA summary table: Time of year $\mathrm{x}$ male independent song rates (songs/hr)

\begin{tabular}{lrrrrr}
\hline \multicolumn{2}{l}{ Whole model: } & & & & \\
$\begin{array}{l}\text { Source of } \\
\text { variation }\end{array}$ & SS & df & $\mathrm{s}^{2}$ & $\mathrm{~F}$ \\
\hline Model & 1189.75 & 23 & 51.72 & $9.47^{*}$ \\
Error & 503.23 & 92 & 5.47 & \\
& & & & \\
Total & 1692.98 & 115 & & \\
\hline
\end{tabular}

Model effects:

Source of MS variation $\mathrm{SS} \quad \mathrm{df}$ num $\mathrm{F}$

\begin{tabular}{lllll}
\hline Month & 936.13 & 7 & 133.73 & $24.45^{*}$
\end{tabular}

Male \& random
$188.96 \quad 16$

11.81

$2.16^{*}$

* Significant at $\mathrm{P}<0.05$

ANOVA summary table: Breeding stage $\mathrm{x}$ combined duet rates (duets/hr)

\begin{tabular}{|c|c|c|c|c|}
\hline \multicolumn{5}{|c|}{ Whole model: } \\
\hline $\begin{array}{l}\text { Source of } \\
\text { variation }\end{array}$ & SS & df & $s^{2}$ & $\mathrm{~F}$ \\
\hline Model & 54.51 & 21 & 1.15 & $2.62^{*}$ \\
\hline Error & 92.11 & 93 & 0.99 & \\
\hline Total & 146.62 & 114 & & \\
\hline
\end{tabular}

Model effects:

\begin{tabular}{lrrrr}
$\begin{array}{l}\text { Source of } \\
\text { variation }\end{array}$ & SS & df & $\begin{array}{r}\text { MS } \\
\text { num }\end{array}$ & F \\
\hline Stage & 27.22 & 5 & 5.44 & $5.50^{*}$ \\
$\begin{array}{l}\text { Pair \& } \\
\text { random }\end{array}$ & 26.83 & 16 & 1.68 & 1.69 \\
\hline
\end{tabular}

*Significant at $\mathrm{P}<0.05$ 
ANOVA summary table: Breeding stage $\mathrm{x}$ combined solo rate (solos $/ \mathrm{hr}$ )

\begin{tabular}{|c|c|c|c|c|}
\hline \multicolumn{5}{|c|}{ Whole model: } \\
\hline $\begin{array}{l}\text { Source of } \\
\text { variation }\end{array}$ & SS & df & $s^{2}$ & $\mathrm{~F}$ \\
\hline Model & 837.68 & 21 & 39.89 & $5.19^{*}$ \\
\hline Error & 715.27 & 93 & 7.69 & \\
\hline Total & 1552.95 & 114 & & \\
\hline
\end{tabular}

Model effects:

Source of MS

variation $\quad \mathrm{SS}$ df num $\mathrm{F}$

\begin{tabular}{lllll}
\hline Stage & 606.90 & 5 & 121.38 & $15.78^{*}$
\end{tabular}

Pair \& random

* Significant at $\mathrm{P}<0.05$

ANOVA summary table: Breeding stage $\mathrm{x}$ female independent song rate (songs/hr)

\begin{tabular}{lrrrrr}
\hline $\begin{array}{l}\text { Whole model: } \\
\begin{array}{l}\text { Source of } \\
\text { variation }\end{array}\end{array}$ & SS & df & $\mathrm{s}^{2}$ & $\mathrm{~F}$ \\
\hline Model & 85.48 & 21 & 4.07 & $3.37^{*}$ \\
Error & 112.48 & 93 & 1.21 & \\
Total & 197.96 & 114 & & \\
\hline
\end{tabular}

Model effects:

\begin{tabular}{lrrrr}
$\begin{array}{l}\text { Source of } \\
\text { variation }\end{array}$ & SS & df & $\begin{array}{c}\text { nS } \\
\text { num }\end{array}$ & F \\
\hline Stage & 46.70 & 5 & 9.34 & $7.72^{*}$ \\
$\begin{array}{l}\text { Female\& } \\
\text { random }\end{array}$ & 37.15 & 16 & 2.32 & $1.92^{*}$ \\
\hline
\end{tabular}

*Significant at $\mathrm{P}<0.05$

ANOVA summary table: Breeding stage $\mathrm{x}$ male independent song (songs/hr)

\begin{tabular}{|c|c|c|c|c|}
\hline \multicolumn{3}{|c|}{ Whole model: } & \multirow[b]{2}{*}{$s^{2}$} & \multirow[b]{2}{*}{$\mathrm{F}$} \\
\hline $\begin{array}{l}\text { Source of } \\
\text { variation }\end{array}$ & SS & $\mathrm{df}$ & & \\
\hline Model & 916.03 & 21 & 43.62 & $5.23^{*}$ \\
\hline Error & 775.56 & 93 & 8.34 & \\
\hline Total & 1691.59 & 114 & & \\
\hline
\end{tabular}

Model effects:

Source of MS

\begin{tabular}{lrrrr} 
variation & SS & df & num & F \\
\hline Stage & 661.32 & 5 & 132.26 & $15.86^{*}$
\end{tabular}

Male \& random 
*Significant at $\mathrm{P}<0.05$

ANOVA summary table: Breeding stage $x$ proportion of songs sung by females

\begin{tabular}{|c|c|c|c|c|}
\hline \multicolumn{5}{|c|}{ Whole model: } \\
\hline $\begin{array}{l}\text { Source of } \\
\text { variation }\end{array}$ & SS & $\mathrm{df}$ & $s^{2}$ & $\mathrm{~F}$ \\
\hline Model & 4.17 & 21 & 0.20 & $8.11 *$ \\
\hline Error & 2.24 & 93 & 0.02 & \\
\hline Total & 6.35 & 114 & & \\
\hline
\end{tabular}

Model effects:

*Significant at $\mathrm{P}<0.05$

ANOVA summary table: Breeding stage $\mathrm{x}$ proportion of songs sung by males

\begin{tabular}{|c|c|c|c|c|}
\hline Whole mo & & & & \\
\hline $\begin{array}{l}\text { Source of } \\
\text { variation }\end{array}$ & SS & $\mathrm{df}$ & $s^{2}$ & $\mathrm{~F}$ \\
\hline Model & 4.00 & 21 & 0.19 & $8.07 *$ \\
\hline Error & 2.20 & 93 & 0.02 & \\
\hline Total & 6.20 & 114 & & \\
\hline
\end{tabular}

\begin{tabular}{lrrrr}
$\begin{array}{l}\text { Source of } \\
\text { variation }\end{array}$ & SS & df & $\begin{array}{c}\text { MS } \\
\text { num }\end{array}$ & F \\
\hline Stage & 2.72 & 5 & 0.54 & $22.55^{*}$
\end{tabular}

Female\&

\begin{tabular}{lllll} 
random & 1.14 & 16 & 0.07 & $2.96 *$ \\
\hline
\end{tabular}

* Significant at $\mathrm{P}<0.05$

ANOVA summary table: Breeding stage $\mathrm{x}$ proportion female created duets

\begin{tabular}{lrrrr}
\hline Whole model: & & & & \\
$\begin{array}{l}\text { Source of } \\
\text { variation }\end{array}$ & $\mathrm{SS}$ & $\mathrm{df}$ & $\mathrm{s}^{2}$ & $\mathrm{~F}$ \\
\hline Model & 2.97 & 21 & 0.14 & 0.90 \\
Error & 12.00 & 76 & 0.16 & \\
$\quad$ & 14.97 & 97 & & \\
\hline
\end{tabular}

\section{Model effects:}

Source of MS

variation SS df num

\begin{tabular}{lllll}
\hline Stage & 2.59 & 5 & 0.52 & $21.91 *$
\end{tabular}

Male \& random

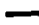


ANOVA summary table: Breeding stage x proportion male created duets

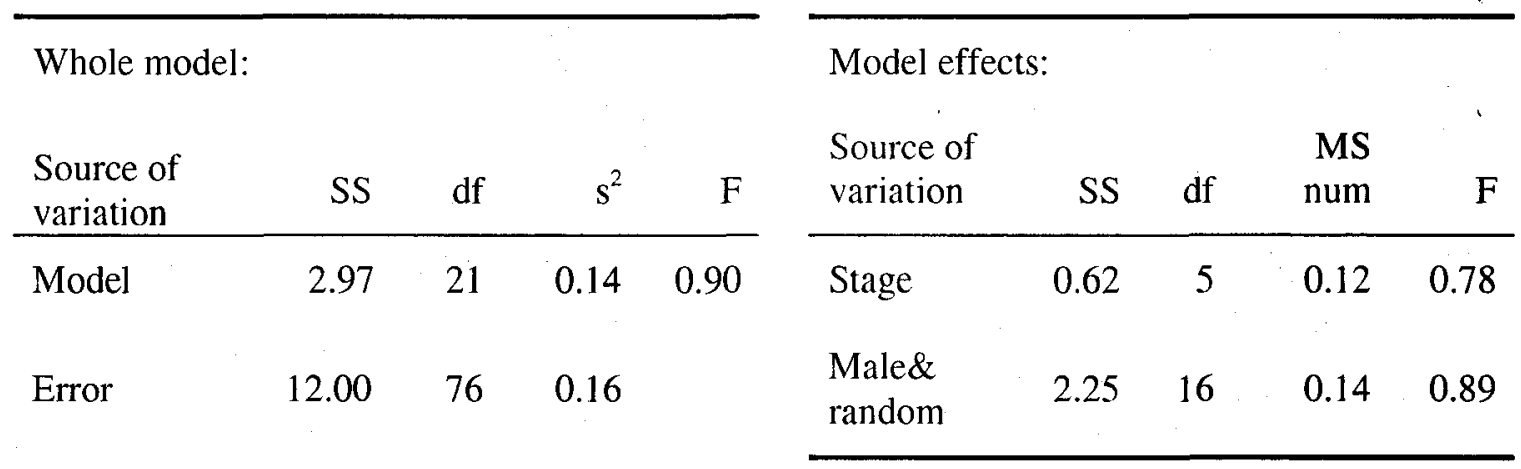

Total $\quad 14.97 \quad 97$

ANOVA summary table: Breeding stage $\mathrm{x}$ female duet responsiveness

\begin{tabular}{|c|c|c|c|c|c|c|c|c|c|}
\hline Whole model: & & & & & Model effe & & & & \\
\hline $\begin{array}{l}\text { Source of } \\
\text { variation }\end{array}$ & SS & $\mathrm{df}$ & $s^{2}$ & $\mathrm{~F}$ & $\begin{array}{l}\text { Source of } \\
\text { variation }\end{array}$ & SS & $\mathrm{df}$ & $\begin{array}{l}\text { MS } \\
\text { num }\end{array}$ & $\mathrm{F}$ \\
\hline Model & 1.94 & 21 & 0.09 & $4.67 *$ & Stage & 1.36 & 5 & 0.27 & $13.73^{*}$ \\
\hline Error & 1.84 & 93 & 0.02 & & $\begin{array}{l}\text { Female\& } \\
\text { random }\end{array}$ & 0.46 & 16 & 0.03 & 1.46 \\
\hline
\end{tabular}

Total $\quad 3.79 \quad 114$

* Significant at $\mathrm{P}<0.05$

ANOVA summary table: Breeding stage $x$ male duet responsiveness

\begin{tabular}{|c|c|c|c|c|c|c|c|c|c|}
\hline \multirow{2}{*}{$\begin{array}{l}\text { Whole model: } \\
\text { Source of } \\
\text { variation }\end{array}$} & \multirow[b]{2}{*}{ SS } & \multirow[b]{2}{*}{ df } & \multirow[b]{2}{*}{$s^{2}$} & \multirow[b]{2}{*}{$F$} & \multicolumn{5}{|c|}{ Model effects: } \\
\hline & & & & & $\begin{array}{l}\text { Source of } \\
\text { variation }\end{array}$ & SS & $\mathrm{df}$ & $\begin{array}{c}\text { MS } \\
\text { num }\end{array}$ & $\mathrm{F}$ \\
\hline Model & 6.70 & 21 & 0.32 & $3.25^{*}$ & Stage & 1.01 & 5 & 0.38 & $3.88^{*}$ \\
\hline Error & 7.17 & 73 & 0.10 & & $\begin{array}{l}\text { Male\& } \\
\text { random }\end{array}$ & 4.79 & 16 & 0.30 & $3.05^{*}$ \\
\hline
\end{tabular}

Total $\quad 13.87 \quad 94$

* Significant at $\mathrm{P}<0.05$ 


\section{Vita}

Name: $\quad$ Stephanie Marie Topp

Place and year of birth: Toronto, Ontario, Canada, 1973

Education: $\quad$ Martingrove Collegiate Institute, 1987-1992

Dalhousie University, 1992 - 1996

B.Sc. Kinesiology

University of British Columbia, 2000-2004

B.Sc. Natural Resources Conservation (Honours)

University of Windsor, 2005-2007

M.Sc. Biological Sciences

Experience:

Graduate assistant, Biology Department, University of Windsor 2006-2007

Rufous-and-white Wren field research, University of Windsor, Area de Conservacion Guanacaste, Costa Rica, 2005-2006

Migrant bird field research, University of British Columbia, Coast Mountains British Columbia, Aug-Oct 2005

Winter Wren field research, University of British Columbia, Mt. Seymour, British Columbia, May-Aug 2004-2005

Salmonid and aquatic ecology field research, University of British Columbia, various locations, May-Aug 2003

Teaching assistant, Forestry Department, University of British Columbia, 2002-2003

Awards:

Society of Canadian Ornithologists and Bird Studies Canada, Fred Cooke Research Award (2006)

American Ornithologists' Union Student Membership Award

National Science \& Engineering Research Council of Canada (NSERC), Post Graduate Scholarship B (2006-2007)

University of Windsor Tuition Scholarship (2005-2007)

NSERC, Canadian Graduate Scholarship (2005-2006)

University of British Columbia (UBC) H. R. MacMillan Prize in Forestry (2004) 
NSERC, Undergraduate Student Research Award (URSA) (2004)

UBC Undergraduate Scholar Program Scholarship (2004)

UBC William John Splan Scholarship in Forestry (2004)

UBC Galt Elkington Memorial Scholarship (2004)

UBC Elizabeth Backman Scholarship in Natural Resources Conservation (2004)

UBC Ted Johnson Scholarship in Forestry (2004)

NSERC, URSA (2003)

UBC Undergraduate Scholar Program Scholarship (2003)

UBC Dean of Forestry Scholarship (2003)

UBC William John Splan Scholarship in Forestry (2003)

UBC H. R. MacMillan Scholarship in Forestry (2003)

UBC David Bell Little Memorial Scholarship (2003)

NSERC, USRA (2002)

UBC C. A. Rowles Alumni Prize (2001)

Publications:

Topp, S. M., L. J. Evans Ogden and K. Martin. (in press). Apparent absence of blood parasites in a population of Winter Wrens in British Columbia. Journal of Field Ornithology.

MacNutt, M. J., S. G. Hinch, A. P. Farrell, and S. Topp. (2004). Effects of thermal acclimation period on repeat swim performance of cutthroat trout (Oncorhyncus clarki clarki). Journal of Fish Biology 65:342-353.

Non-refereed:

Topp, S. M. (October 2006). Animal Communication Networks (ed. Peter McGregor). Book review. Picoides 19:43-44. 